\title{
Complete Genome Sequencing of Field Isolates of Peste des Petits Ruminants Virus from Tanzania Revealed a High Nucleotide Identity with Lineage III PPR Viruses
}

\author{
Edson Kinimi ${ }^{1,2,3, *(\mathbb{D})}$, Mana Mahapatra ${ }^{4}\left(\mathbb{D}\right.$, Tebogo Kgotlele ${ }^{3} \mathbb{D}$, Mariam R. Makange ${ }^{3}$, Chandana Tennakoon ${ }^{4}$, \\ Felix Njeumi ${ }^{5}$, Steven Odongo ${ }^{6}$, Serge Muyldermans ${ }^{7}\left(\mathbb{D}\right.$, Richard Kock ${ }^{8}\left(\mathbb{D}\right.$, Satya Parida ${ }^{1,4,5}{ }^{(D)}$, \\ Mark Rweyemamu ${ }^{1}$ and Gerald Misinzo ${ }^{1,3, * \text { (D) }}$
}

1 SACIDS Africa Centre of Excellence for Infectious Diseases, SACIDS Foundation for One Health, Sokoine University of Agriculture, P.O. Box 3297, Morogoro 67125, Tanzania; satya.parida@fao.org (S.P.); mark.rweyemamu@sacids.org (M.R.)

2 Department of Veterinary Physiology, Biochemistry and Pharmacology, College of Veterinary Medicine and Biomedical Sciences, Sokoine University of Agriculture, P.O. Box 3017, Morogoro 67125, Tanzania

3 Department of Veterinary Microbiology, Parasitology and Biotechnology, College of Veterinary Medicine and Biomedical Sciences, Sokoine University of Agriculture, P.O. Box 3019, Morogoro 67125, Tanzania; tkgotlele@gmail.com (T.K.); mirrichy@gmail.com (M.R.M.)

check for updates

Citation: Kinimi, E.; Mahapatra, M.; Kgotlele, T.; Makange, M.R.;

Tennakoon, C.; Njeumi, F.; Odongo,

S.; Muyldermans, S.; Kock, R.; Parida,

S.; et al. Complete Genome

Sequencing of Field Isolates of Peste des Petits Ruminants Virus from

Tanzania Revealed a High Nucleotide Identity with Lineage III PPR Viruses. Animals 2021, 11, 2976. https:// doi.org/10.3390/ani11102976

Academic Editors: Clive Julian Christie Phillips and Margarita Martín Castillo

Received: 29 June 2021

Accepted: 12 October 2021

Published: 15 October 2021

Publisher's Note: MDPI stays neutral with regard to jurisdictional claims in published maps and institutional affiliations.

Copyright: (c) 2021 by the authors. Licensee MDPI, Basel, Switzerland. This article is an open access article distributed under the terms and conditions of the Creative Commons Attribution (CC BY) license (https:// creativecommons.org/licenses/by/ $4.0 /)$.
4 The Pirbright Institute, Ash Road, Pirbright, Woking GU24 0NF, UK; mana.mahapatra@pirbright.ac.uk (M.M.); chandana.tennakoon@pirbright.ac.uk (C.T.)

5 Food and Agriculture Organization of the United Nations (FAO), Viale delle Terme di Caracalla, 00153 Rome, Italy; Felix.Njeumi@fao.org

6 Department of Biotechnical and Diagnostic Sciences, College of Veterinary Medicine, Animal Resources and Biosecurity (COVAB), Makerere University, Kampala P.O. Box 7062, Uganda; opodongo@yahoo.co.uk

7 Laboratory of Cellular and Molecular Immunology, Vrije Universiteit Brussel, Pleinlaan 2, 1050 Brussels, Belgium; Serge.Muyldermans@vub.be

8 The Royal Veterinary College, University of London, Hawkshead Lane, North Mymms, Hertfordshire, Hatfield AL9 7TA, UK; Rkock@rvc.ac.uk

* Correspondence: kinimi.edson@sacids.org (E.K.); gerald.misinzo@sacids.org (G.M.)

Simple Summary: Peste des petits ruminants virus (PPRV) causes a highly devastating disease, peste des petits ruminants (PPR), in sheep and goats, which is targeted for global control and eradication. However, in many developing countries, access to expensive sequencing technologies is limited and is compounded by difficulties in transporting clinical samples across international borders. Oxford nanopore MinION is a relatively cheap sequencing technology using portable devices that require minimal supporting laboratory infrastructure or technical expertise for sample preparation and rapid sequencing. In this study, Oxford nanopore MinION sequencing was carried out to generate complete genomes of PPRV from archived PPRV-positive samples collected from PPR outbreaks in goats in Ngorongoro and Momba districts in Tanzania during 2016 and 2018, respectively. Complete genomes of PPRV of 15,948 nucleotides long were generated within four hours of sequencing. The phylogenetic analysis of the complete genomes revealed a high nucleotide identity (96.19-99.24\%) with lineage III PPR viruses currently circulating in East Africa, indicating a common origin. The Oxford nanopore MinION sequencer can be deployed to overcome diagnostic and surveillance challenges in developing countries in the PPR Global Control and Eradication program. However, the coverage depth was uneven across the genome and amplicon dropout was observed between the matrix (M) and fusion (F) genes. Thus, larger field studies are needed to allow the collection of sufficient data to assess the robustness of nanopore sequencing technology.

Abstract: Peste des petits ruminants virus (PPRV) causes a highly devastating disease of sheep and goats that threatens food security, small ruminant production and susceptible endangered wild ruminants. With policy directed towards achieving global PPR eradication, the establishment of cost-effective genomic surveillance tools is critical where PPR is endemic. Genomic data can provide sufficient in-depth information to identify the pockets of endemicity responsible for PPRV persistence and viral evolution, and direct an appropriate vaccination response. Yet, access to 
the required sequencing technology is low in resource-limited settings and is compounded by the difficulty of transporting clinical samples from wildlife across international borders due to the Convention on International Trade in Endangered Species (CITES) of Wild Fauna and Flora, and Nagoya Protocol regulations. Oxford nanopore MinION sequencing technology has recently demonstrated an extraordinary performance in the sequencing of PPRV due to its rapidity, utility in endemic countries and comparatively low cost per sample when compared to other whole-genome (WGS) sequencing platforms. In the present study, Oxford nanopore MinION sequencing was utilised to generate complete genomes of PPRV isolates collected from infected goats in Ngorongoro and Momba districts in the northern and southern highlands of Tanzania during 2016 and 2018, respectively. The tiling multiplex polymerase chain reaction (PCR) was carried out with twenty-five pairs of long-read primers. The resulting PCR amplicons were used for nanopore library preparation and sequencing. The analysis of output data was complete genomes of PPRV, produced within four hours of sequencing (accession numbers: MW960272 and MZ322753). Phylogenetic analysis of the complete genomes revealed a high nucleotide identity, between 96.19 and $99.24 \%$ with lineage III PPRV currently circulating in East Africa, indicating a common origin. The Oxford nanopore MinION sequencer can be deployed to overcome diagnostic and surveillance challenges in the PPR Global Control and Eradication program. However, the coverage depth was uneven across the genome and amplicon dropout was observed mainly in the GC-rich region between the matrix (M) and fusion (F) genes of PPRV. Thus, larger field studies are needed to allow the collection of sufficient data to assess the robustness of nanopore sequencing technology.

Keywords: peste des petits ruminants virus; PPR; Oxford nanopore MinION; diagnosis; complete genome; sequencing; Tanzania

\section{Introduction}

Peste des petits ruminants (PPR) is a highly contagious viral disease of wild and domestic small ruminants caused by peste des petits ruminants virus (PPRV), a pathogen targeted for global control and eradication by 2030 [1]. PPR has been reported at an increased rate from its historical distribution across Africa and Asia into new areas where it has not been detected previously [2,3] since the global eradication of rinderpest. Owing to its spread and expansion beyond its known geographical boundaries, PPR causes significant economic losses between USD 1.2 and 1.7 billion globally per year, due to decreased production and animal death, as well as the cost required to overcome the disease [4]. Approximately one third of the economic losses occur in Africa and a quarter in South Asia, and the rest in East Asia, the Middle East and West Eurasia including Turkey, with costs being incurred predominantly by subsistence farmers $[5,6]$. However, an investment of USD 7.1 billion could be recovered within five years of a successful global eradication, with a 33.8 benefit:cost ratio that makes PPR eradication economically feasible [4]. Unfortunately, the delay of the response following rinderpest eradication and following the identification of PPR spread across disease-free zones and susceptible animal populations such as camelidae, suidae, and bovinae, has increased the likely eradication cost [1]. For instance, the financial losses associated with an outbreak of PPR in critically endangered species of saiga antelope (Saiga tatarica mongolica) in Mongolia were estimated at USD 7.27 million [1]. In order to avoid unprecedented financial losses in both wild and domestic small ruminants, an intensive, mass vaccination programme is required to reach and maintain high levels of herd immunity in sheep and goats [7]. It would be more efficient to target vaccination to identified pockets of endemicity responsible for PPRV persistence and create high levels of vaccination immunity in these defined populations, as was successfully carried out in the last phase of rinderpest eradication $[7,8]$. The identification of pockets of endemicity responsible for PPRV persistence requires an active surveillance programme in susceptible animal populations with rapid and cost-effective diagnostic tools. 
The development of the necessary tools for PPR control, including vaccines, diagnostics and therapeutics, greatly depends on in-depth genomic information on the virus [9]. Unfortunately, few complete genomes of PPRV exist, and very few from East Africa, despite the existence of lineage II, III and IV PPRV [10]. The publicly available PPRV sequences from Tanzania were partial sequences, based on nucleoprotein sequencing, to study the phylogeny of PPRV isolates (Table 1). This restricts the ability to define important changes in the genome outside of pre-defined target genetic markers. Nevertheless, genetic changes could be important in viral evolution studies and in the development of novel diagnostic and therapeutic tools for PPR $[9,11]$. Interestingly, Oxford nanopore MinION sequencing is a rapid and relatively cheap technology that uses portable devices that require minimal supporting laboratory infrastructure or technical expertise for sample preparation [12]. The relatively low abundance of viral nucleic acids compared to that of host nucleic acids in clinical samples often necessitates the analysis of a substantial amount of sequence data, reflected in analysis times and associated costs [13]. In this study, the ARTIC method, based on tiling multiplex PCRs that were previously used to enrich PCR amplicons for Zika virus, Ebola virus and severe acute respiratory syndrome coronavirus-2 (SARS-CoV-2), was adopted to generate the complete genomes of field isolates of PPR $[13,14]$. Using this advanced approach, by assessing the long overlaps among multiplex amplicons, the accurately assembled and complete viral genome can be obtained, which can facilitate the rapid genomic surveillance of PPRV for better understanding its pathogenicity, evolution and transmission. Although a protocol for Oxford nanopore sequencing of PPRV has been established, adoption of the technology has been limited due to concerns around accuracy and high error rates associated with homopolymer lengths [15]. The nanopore device exhibits lower read-level sequencing accuracy than its short-read platform counterparts [16]. Moreover, the longest untranslated intergenic region between $M$ and $F$ genes, with about 66-72\% GC content, impedes full-genome sequencing with next-generation sequencing technologies such as Illumina and Oxford nanopore MinION [9,17]. This region is an extremely difficult PCR target to sequence due to repetitive sequences and secondary DNA structure formation. In order to circumvent this deficiency, a method was successfully developed to amplify the GC-rich fragments (F7, F8 and F9) by redesigning long-read primers targeting the GC-rich region, prior to the full-genome sequencing in another study (manuscript in preparation).

The etiological agent PPRV belongs to the genus Morbillivirus of the family Paramyxoviridae [18]. The PPRV genome is linear, non-segmented, negative-sense, single-stranded RNA, which is 15,948 nucleotides long [19]. Its genome length complies with hexamer length and the "rule of six," in which the total number of nucleotides must be a multiple of six for the virus to replicate efficiently in infected cells [19]. However, a longer variant of PPRV of 15,954 nucleotides long has been reported in China [20]. The tolerance for variation is particularly constrained in the genomic termini, as they contain essential elements for replication, such as the signal for encapsidation and promoters for genome and antigenome replication [20,21]. Generally, this genome comprises six genes in order of $3^{\prime}-\mathrm{N}, \mathrm{P}, \mathrm{M}, \mathrm{F}$, $\mathrm{H}, \mathrm{L}-5^{\prime}$, with each gene coding for a distinct structural protein, the exception being the phosphoprotein $(\mathrm{P})$ gene $[9,19]$ which also codes for additional non-structural proteins. These non-structural proteins, designated $\mathrm{C}$ and $\mathrm{V}$, are generated through alternative start codons (leaky scanning) and RNA editing, respectively [22]. The encoded proteins bear the acronym of the respective gene of origin; the nucleoprotein $(\mathrm{N})$, the phosphoprotein $(\mathrm{P})$, the matrix protein $(\mathrm{M})$, the fusion protein $(\mathrm{F})$, the haemagglutinin protein $(\mathrm{H})$ and the RNA-dependent RNA polymerase also known as large protein (L). The $\mathrm{N}$ protein is abundant in PPRV-infected cells because the $N$ gene is located near the $3^{\prime}$ proximal genomic promoter, and hence it is the most transcribed gene [23]. Given its abundance and antigenic stability, the $\mathrm{N}$ protein is frequently used in PPR diagnostic development and is the most appropriate gene for molecular characterization of closely related isolates [24]. Based on the partial molecular genetic characterization of $\mathrm{N}$ and fusion $\mathrm{F}$ protein genes, PPRV has been grouped into four distinct lineages (I, II, III and IV) that exist as a single serotype [25-27]. 
The current geographical distribution of PPRV lineages shows lineages I, II and III as restricted primarily to the African continent [10], whilst lineage IV is found throughout Asia and the Middle East, although early detection includes Central Africa as well as contemporary detections in North and sub-Saharan Africa [2,10]. In 2008, lineage IV PPRV was reported to have caused a devastating epidemic of PPR in Morocco [28]. Phylogeographic analysis suggests that lineage IV PPRV has spread from Eastern Africa, most likely from the Sudan 2000 outbreak, into Northern Africa, resulting in the 2008 Moroccan outbreak [29]. Later in 2009, lineage IV was also detected in several countries in sub-Saharan Africa [25,30-32], where there was no clear-cut association with trade of movement from either Morocco, the Middle East or South Asia. In the 1990s, Tanzania was free from PPR based on comprehensive serological investigations in goats and sheep [33]. In 2008, PPR was serologically confirmed in northern Tanzania for the first time [34]. However, a retrospective study that was conducted on archived samples collected from Ngorongoro district between 1998 and 2004 found antibodies against PPRV already present in samples collected in 2004, indicating that PPR might have been present in Tanzania before it was officially confirmed in 2008 [35]. Molecular confirmation of PPRV was carried out at a much later time (2010) than would have been expected for the correct identification of outbreaks (Table 1 ).

Since the 1980s, the diagnosis of PPR has constantly been improved through advances in material sciences, genomics, bioinformatics, biotechnology, nanotechnologies, microfluidics and the miniaturization of electronic devices [36]. The first partial nucleotide sequence of PPRV was generated from the cloned N gene of PPRV /N/75/1 vaccine strain in 1994, which was followed by the sequencing of the F protein gene $[37,38]$. The sequencing of the $N$ and $F$ genes was pivotal in the development of important molecular diagnostic tools for PPR detection and confirmation [26,39]. More importantly, in 2005, a complete genome of PPRV was publicly available for the first time using Sanger standard methods [19]. Sanger dideoxynucleotide cycle sequencing has been a standard method for the sequencing of PPRV and confirmation of sequences that are difficult to generate with other methods $[10,19,40]$. With recent advances in sequencing technologies, the complete genomes of PPRV isolates are now being generated using next-generation sequencing technologies, mainly Illumina, and recently Oxford nanopore MinION [17]. The Oxford nanopore MinION sequencing technology has been proven powerful in the genetic characterization of infectious disease agents, including PPRV [13]. The establishment and deployment of nanopore sequencing of PPRV provides an opportunity for the molecular epidemiological surveillance of PPR in resource-limited settings and challenging geographical landscapes, due to its rapidity, improved accuracy and relatively low sequencing cost per sample [12]. This sequencing tool may play a significant role in controlling PPR outbreaks, enabling the detection of cryptic foci, inadequate vaccine deployment and other challenges in the midst of an eradication campaign. Moreover, Oxford nanopore has recently shown a capability for sequencing a full or nearly full genome of PPRV in a single sequencing run within $4 \mathrm{~h}$ of sequencing. This provides an opportunity for genomic surveillance of PPRV in real time, necessary for the early implementation of control measures in low-income and in resource-constrained countries, where PPR is endemic.

The present study was undertaken to generate complete genomes of PPRV isolates collected from goat in the Ngorongoro and Momba districts of Tanzania in 2016 and 2018, respectively, using the Oxford nanopore MinION sequencer. The use of the Oxford nanopore MinION sequencer permits sequencing of PPRV in resource-limited settings and in addition makes the production of a complete genome possible within a day. The availability of the full genome of PPRV provides important insight in viral evolution, transmission routes and the implementation of appropriate control measures. 
Table 1. Molecular epidemiological studies of peste des petits ruminants in different districts of Tanzania, based on partial N gene and complete genome sequence analysis from 2010 to 2020. The sequences from these studies clustered into three lineages (II, III and IV) and they were isolated from domestic sheep and goats, and a wild small ruminant (Grant's gazelle).

\begin{tabular}{|c|c|c|c|c|c|}
\hline Region/District & Study Period & Host & Sequence & Lineage & References \\
\hline $\begin{array}{l}\text { Arusha, Kilimanjaro, } \\
\text { Manyara and Tanga }\end{array}$ & 2010 & sheep and goats & partial & III & [40] \\
\hline Tandahimba and Newala & 2011 & sheep and goats & - & - & [41] \\
\hline Mvomero & 2013 & sheep and goats & - & - & [42] \\
\hline Ngorongoro and Mvomero & 2013 & goats & partial & III & [43] \\
\hline Ngorongoro & 2014 & sheep and Grant's gazelle & partial & II & [44] \\
\hline Tandahimba & 2015 & sheep and goats & partial & II and IV & [45] \\
\hline Ngorongoro & 2015 & sheep and goats & partial & III & [46] \\
\hline Ngorongoro & 2016 & sheep and goats & - & - & [47] \\
\hline Mbeya, Iringa, Dodoma & & & & & \\
\hline $\begin{array}{c}\text { Morogoro, Pwani Serengeti, } \\
\text { Tanga and Arusha }\end{array}$ & 2018 & sheep and goats & - & - & [48] \\
\hline Mvomero & 2020 & sheep and goats & complete & III & [17] \\
\hline
\end{tabular}

\section{Materials and Methods}

\subsection{Sample Source Description and Storage}

The nasal swab samples used in this study were collected from goats in Chilulumo ward in Momba district and the Loliondo area of Ngorongoro district in 2018 and 2016, respectively. Momba district is located in the north-western part of the Songwe region of the Southern highlands of Tanzania (Figure 1). The district borders the Rukwa region and Zambia to the west, with Mbozi district to the east, Chunya district to the north and Ileje district to the south, whilst the Ngorongoro district is located in the northern part of the country in the Arusha Region. The samples collected from the Loliondo area of Ngorongoro district in 2016 were previously described and tested by Kgotlele et al. [47]. However, Momba samples were collected during PPR sero-survey in September, 2018. The key clinical signs investigated in 13 goats suspected of PPRV infection include; fever, nasal and ocular discharges, diarrhoea and laboured breathing (Figure 2). The rectal temperature of clinically sick goats ranged between 40 and $41.5^{\circ} \mathrm{C}$, with an average temperature of $41^{\circ} \mathrm{C}$. It was noted that all sick goats $(n=51)$ recruited for study were an indigenous breed aged between 1 and 2 years. The study recorded 10 deaths with case fatality rates of $19.6 \%$ and $100 \%$ morbidity. The nasal swabs from live goats were collected in universal viral transport medium (BD Biosciences, Maryland, USA) followed by flicking to dislodge cells from the swabs, and were stored at $-80{ }^{\circ} \mathrm{C}$ until RNA extraction was undertaken.

\subsection{Sample Selection}

Seventy-three samples that were previously screened for PPR from different outbreaks in Tanzania were used in this study. When the samples were re-tested by conventional reverse transcription polymerase chain reaction (RT-PCR) prior to full-genome sequencing, most were negative for PPRV, indicating RNA degradation due to temperature fluctuations in our ultralow temperature freezers (freeze and thaw) as a result of frequent power cuts [26]. For example, all 36 samples collected during a PPR outbreak in Tandahimba in 2011 were negative. A total of 7 out of 24 samples collected during a PPR outbreak in Ngorongoro were positive. Out of these 7 PPRV-positive samples, only one had a strong visible band on agarose gel electrophoresis after RT-PCR. Similarly, only 1 out of 13 samples collected during a PPR outbreak in Momba in 2018 produced a strong visible band on agarose gel electrophoresis after RT-PCR. Thus, in total we had 8 PPRV-positive samples with only 2 strongly positive samples that yielded full PPRV genomes after next-generation sequencing. The remaining samples had very low PPRV genome coverage. 


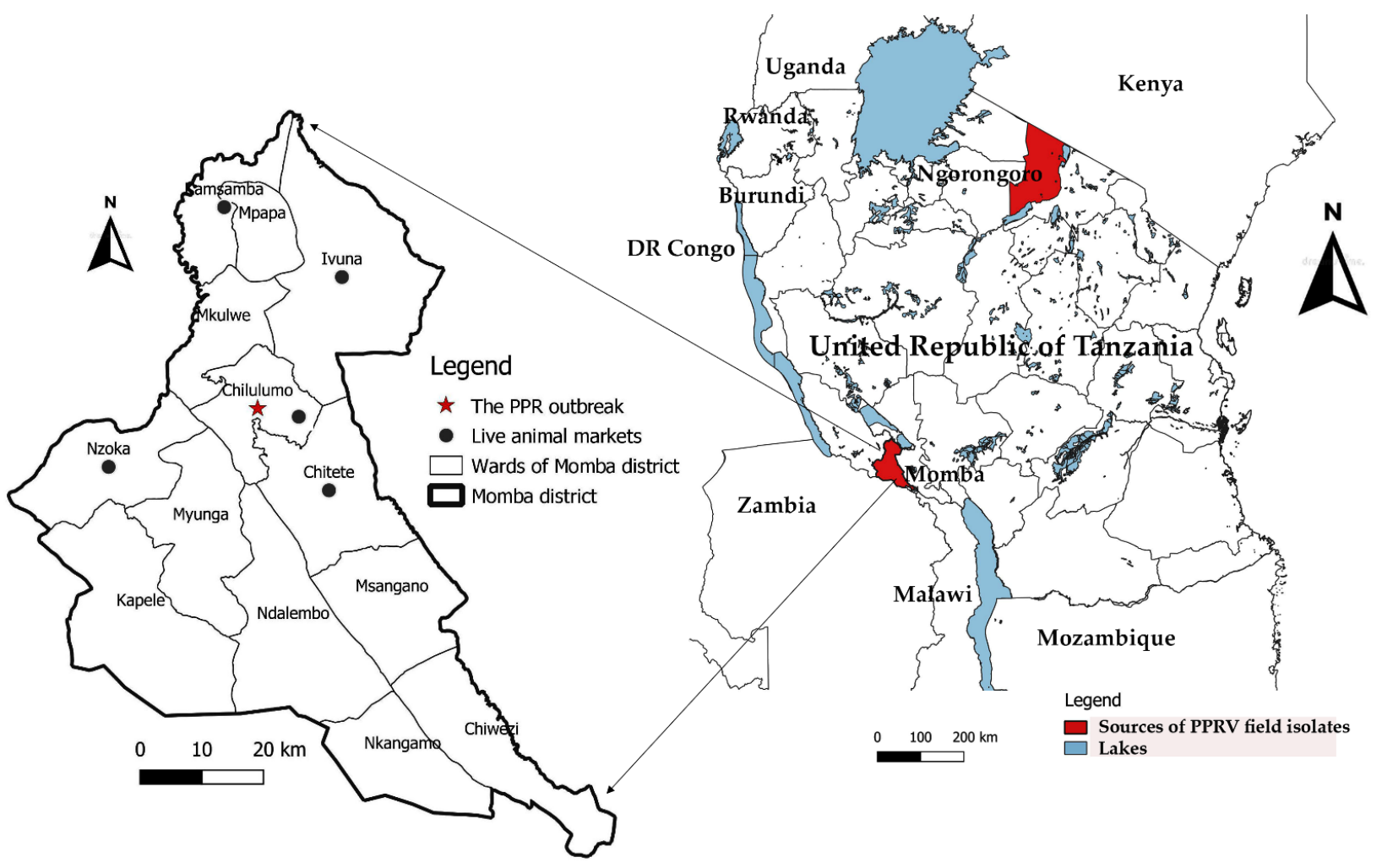

Figure 1. A map of Tanzania showing sources of PPRV field isolates used in this study. The archived PPRV-positive samples analysed in this study were collected from goats in Chilulumo ward in Momba district and in Loliondo area in Ngorongoro district, marked in red.
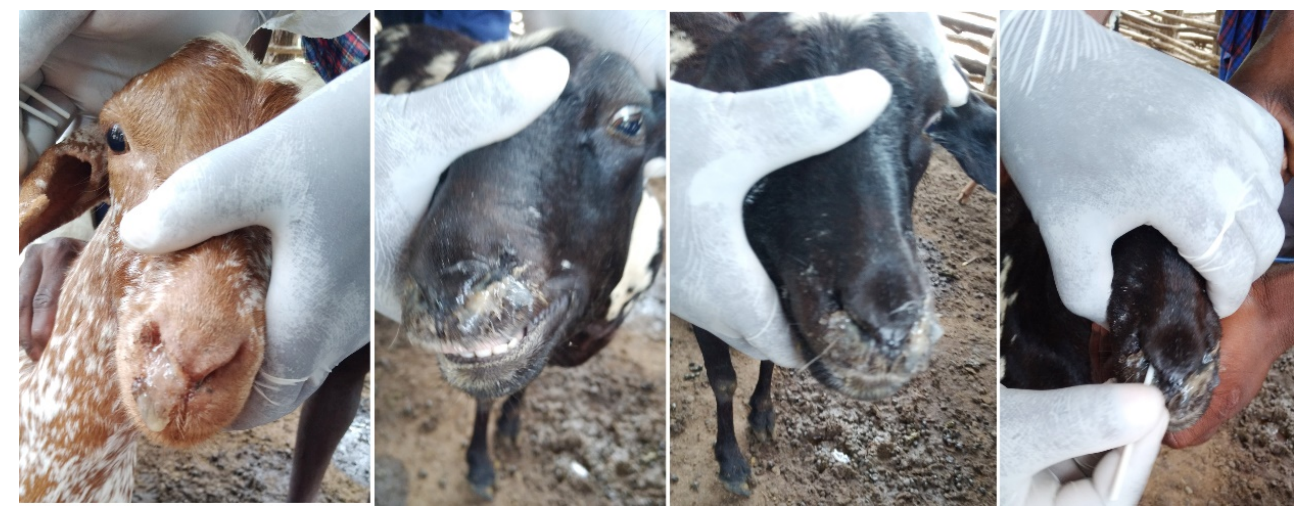

Figure 2. Nasally discharging goats suggestive of peste des petits ruminants virus (PPRV) infection, during a peste des petits ruminants (PPR) sero-survey at Chilulumo ward in the Momba district, in 2018. The nasal swab samples were collected and tested for the presence of PPRV infection. The PPR-positive samples were stored at $-80{ }^{\circ} \mathrm{C}$ for further research.

\subsection{RNA Extraction, cDNA Synthesis and PCR Amplification}

Total RNA was extracted using the QIAamp Mini kit (Qiagen, Hilden, Germany) according to the manufacturer's instructions. The cDNA synthesis was carried out using the Superscript IV First-Strand Synthesis System (Invitrogen, Paisley, UK) using $11 \mu \mathrm{L}$ of RNA, according to the full wet lab protocol [17]. Polymerase chain reaction (PCR) nucleotide amplification reactions were performed using the Q5 Hot Start High Fidelity Polymerase (New England BioLabs, UK). Twenty two pairs of multiplex primers of $800 \mathrm{bp}$ with an overlap of $100 \mathrm{bp}$ were used as previously described by Torsson et al. [17], plus three newly designed pairs of primers targeting the long guanine cytosine untranslated region (GC-rich) of PPRV (Table 2). Briefly, two separate PCR reactions were carried out 
for each PPRV-positive sample. Two pools of primers were made; 'pool 1' contained eleven primers that generated the odd-numbered tiled amplicons, while 'pool 2' contained eleven primers that generated the even-numbered tiled amplicons for the $800 \mathrm{bp}$ set. The three primers targeting the GC-rich fragments (F7, F8 and F9) were used separately in each PCR tube. The PCR reactions were performed using a nexus gradient master thermocycler (Eppendorf AG Hamburg, Germany). The resulting PCR amplicons were pooled and then purified using AMPure XP magnetic beads (Beckman Coulter, Redwood, USA) with a 1.8x bead ratio and quantified using Qubit 1.0 Fluorometer dsDNA HS assay (Thermo Fisher Scientific, Waltham, USA). The PCR amplicons were run on a $1 \%$ agarose gel and visualized using a Gel Doc ${ }^{\mathrm{TM}}$ EZ Imager agarose gel imaging system (Bio-Rad, Hercules, CA, USA). The detailed methods for reverse transcription, tiled multiplex PCR and library ligation were followed according to the full wet laboratory protocol available (doi.org/10.17504/protocols.io.pnxdmfn) since April 2021.

Table 2. List of long-read primers, 7, 8 and 9, that were developed to amplify an extremely difficult PCR target, the GC-rich region between matrix $(\mathrm{M})$ and fusion $(\mathrm{F})$ protein genes of PPRV.

\begin{tabular}{|c|c|c|c|c|c|c|c|}
\hline \multirow{2}{*}{ Primer Name } & \multirow{2}{*}{ Fragments } & \multirow{2}{*}{ Sequence $\left(5^{\prime}\right.$ to $\left.3^{\prime}\right)$} & \multirow{2}{*}{$\operatorname{Tm} *$} & \multirow{2}{*}{ GC\% } & \multicolumn{2}{|c|}{ Position on Genome } & \multirow{2}{*}{$\begin{array}{c}\text { Fragment } \\
\text { Size (bp) }\end{array}$} \\
\hline & & & & & Start & End & \\
\hline PPRV7LK & \multirow[b]{2}{*}{ F7 } & CAACAACACTCCGCTGTCCT & 60.30 & 55.00 & 3778 & 3796 & \multirow[b]{2}{*}{770} \\
\hline PPRV7RK & & GAGTGGCTGTGTTGGTGCT & 60.53 & 57.89 & 4548 & 4530 & \\
\hline PPRV8LK & \multirow[b]{2}{*}{ F8 } & CAAGCCGTCCTACAGCCATC & 60.81 & 60.00 & 4353 & 4372 & \multirow[b]{2}{*}{895} \\
\hline PPRV8RK & & GTCCTCCCTCGGTCTGTCT & 60.00 & 63.16 & 5248 & 5229 & \\
\hline PPRV9LK & \multirow[t]{2}{*}{ F9 } & GAGGACACCCAACCACCGAAAC & 59.00 & 59.09 & 4972 & 4993 & \multirow{2}{*}{815} \\
\hline PPRV9RK & & ACAGAGCATCCTCTACAGGCTT & 55.00 & 50.00 & 5787 & 5766 & \\
\hline
\end{tabular}

* Tm; melting temperature, GC\%; GC content.

\subsection{Nanopore Library Preparation and Sequencing}

Sequencing libraries were prepared using the SQK-LSK109 ligation sequencing kit and EXP-NBD104 native barcode expansion (Oxford Nanopore Technologies, UK) following the nanopore sequencing protocol [17]. The concentration of 0.12 pmol PCR products was diluted in $25 \mu \mathrm{L}$ of nuclease-free water. This generated $60 \mathrm{ng}$ of the PCR product in $25 \mu \mathrm{L}$ water for our amplicons (800 bp) (https://nebiocalculator.neb.com/ accessed on 11 November 2020). The final concentration of the DNA library was $42 \mathrm{fmol}$. Briefly, the purified PCR amplicons were repaired and A-tailed using the NEB Next Ultra II End Repair/dA-Tailing module (New England BioLabs, Ipswich, MA, USA). Native barcodes and adaptors were ligated to end-repaired PCR amplicons using Blunt/TA Ligase Master Mix (New England BioLabs, Ipswich, MA, USA), to generate the nanopore library. The library was then sequenced on a MinION Flow cell for $4 \mathrm{~h}$. The nanopore sequencing raw read datasets were generated in standard fast 5 format. The nanopore raw reads were basecalled and demultiplexed to generate fastq files using GUPPY software built in MinIT.

\subsection{Nanopore Dataset Analysis}

The composition and quality of reads were assessed using nanoplot and qScore, and the reads below a qScore of 7 were removed by the EPI2ME software version 2019.7.9, (as per ONT pass/fail threshold) before downstream analysis (PycoQC (https: / / usegalaxy.org, accessed on 5 January 2021). Additional demultiplexing and adaptor removal were performed using porechop in NanoGalaxy platform $[49,50]$. The trimmed nanopore reads were checked for purity using Q-score in the nanoplot $[49,51]$. The reads were aligned to the PPRV reference genomes (RefSeq accession number: KM463083) using minimap2 version 2.17 [52]. The resulting binary alignment map (BAM) file was sorted and converted into an indexed BAM file for additional processing with samtools version 1.9 [53]. Following this, a consensus sequence was created by obtaining the majority vote for the bases from the pileup of the BAM file. The Katuali (https://github.com/nanoporetech/ katuali, accessed on 7 January 2021) pipeline was used to assemble the genome. The 
reads were assembled with Canu version 2.0 [54] and polished with Racon and Medaka (https:/ / github.com/nanoporetech/medaka, accessed on 7 January 2021) [55]. For the Momba/Tanzania/2018 PPRV field isolate, the missing $5^{\prime}$ region (from $15890 \mathrm{bp}$ onwards) in the nanopore assembly was completed using the matching region from the consensus. When the final assembly was compared with KM463083, 11 indels were found. We did not observe any clustering of the indels. We manually removed the indels where the frequency of the reads supporting an indel was below $40 \%$ and the frequency of the reads that did not support the indel exceeded $60 \%$. The browser extensible data (BED) files were created, representing the coverage of the sequence reads against the reference genome, and the results were visualized using integrative genomics viewer (IGV). Finally, the consensus sequences were annotated using genome annotation transfer utility [56] and whole-genome comparison was performed using the basic local alignment search tool (NCBI BLAST version 2.12.0, Rockville Pike, MD, USA). With comparable sequences from GenBank, a phylogenetic tree was constructed using the Maximum likelihood method, and the Kimura 2-parameter model with a bootstrap frequency of 1000 replicates, as implemented in MEGA X software [57].

\subsection{Temporal Phylogenetics}

To identify the nearest common ancestor and hence likely dates of divergence, the Tanzania/Momba/2018 and Tanzania/Ngorongoro/2016 (Accession Numbers: (MZ322753 and MW960272) sequences were compared using the coalescent-based Bayesian Markov chain Monte Carlo (MCMC) approach to selected complete genomes of PPRV available in GenBank ( $n=38)$ [58]. The gamma distribution and general time-reversible nucleotide substitution model for rate variation and the proportion of invariant sites were selected on the basis of Akaike information criterion scores. Bayesian time-scaled phylogenetic analysis molecular evolutionary rate and divergence times were estimated. A Bayesian maximum clade credibility (MCC) phylogenetic tree was constructed by using Bayesian Markov chain Monte Carlo (MCMC) analysis and Bayesian evolutionary analysis sampling trees (BEAST), and the Tree Annotator software package v1.10.4 (Auckland, New Zealand). For the sequence dataset, the best-fit nucleotide substitution model was determined on the basis of Akaike information criterion scores using JModel Test software v2.1.4 (Boston, MA, USA), as previously described [59]. An input file for BEAST analysis was obtained by using Bayesian evolutionary analysis utility software, BEAUti v1.10.4 (Auckland, New Zealand) in which sequences were tip dated according to the year of collection. The relaxed molecular clock with coalescent exponential growth was the most appropriate model for this analysis, as previously reported $[29,59]$. The Bayesian analyses were run for 50,000,000 iterations sampled every 5000 in duplicate; duplicate runs were combined for final analysis with effective sample size (ESS > 200) and were assessed for their proper mixing, convergence and consistency by Tracer v1.7.2 with 10\% burn in. The two individual runs were combined by using LogCombiner v1.10.4 in the BEAST software package (Auckland, New Zealand). The nucleotide substitution rate (substitutions/site/year) and the time to the most recent common ancestor (TMRCA) (year) values were obtained from Tracer v1.7.2. The posterior tree distributions were summarized by using TreeAnnotator v1.10.4 and exclusion of the first $10 \%$ of the trees as burn in. Phylogenetic MCC tree with median node heights were visualized in FigTree software v1.4.2 (Auckland, New Zealand). The phylogenetic MCC tree in Newick file format together with metadata file with accession number and country of origin were uploaded to PastML for ancestral state reconstruction (https:/ / pastml. pasteur.fr/, accessed on 2 May 2021).

\section{Results}

\subsection{Nucleotide Amplification}

Out of eight archived PPRV-positive samples screened for PPR, only two samples had strong bands on agarose gel electrophoresis using gene-specific primers (NP3/NP4) targeting the nucleocapsid protein gene. The two positive samples were collected from 
goats in Ngorongoro and Momba districts in the northern and southern highland of Tanzania. The cDNA obtained from these positive samples were used subsequently in tiling multiplex PCR. Analysis of the PCR amplicons on agarose gel electrophoresis exhibited strong PCR bands of expected size ( $~ 800 \mathrm{bp})$, confirming successful amplification of the fragments (Figure 3). However, relatively faint bands were observed in the PCR fragments that targeted the GC-rich region of PPRV.

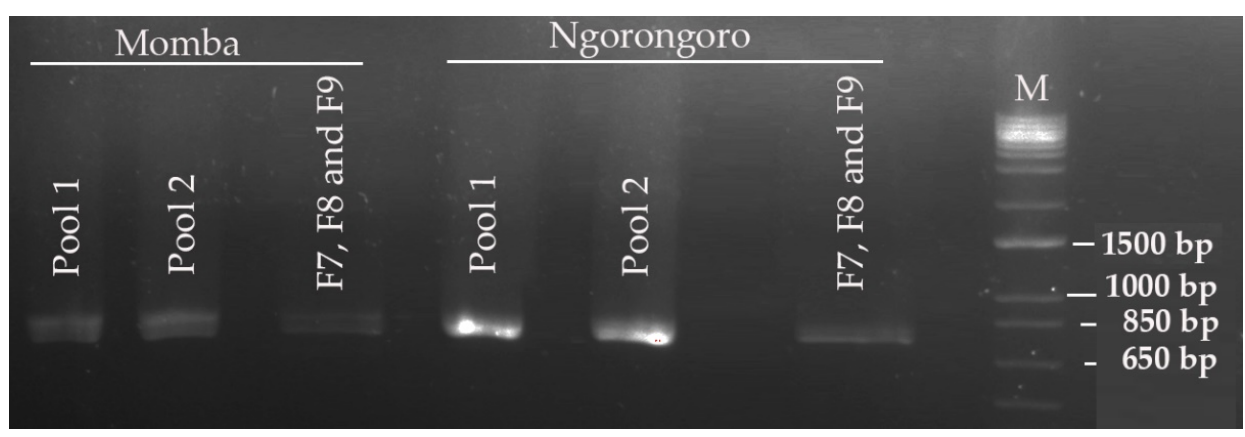

Figure 3. Gel electrophoresis of tiling multiplex polymerase chain reaction (PCR) amplification products of peste des petits ruminants virus isolates from Momba and Ngorongoro districts in Tanzania. The PCR amplicons indicate an expected band size of around $800 \mathrm{bp}$ in accordance with primer targets.

\subsection{Long-Read Nanopore Sequencing of PPRV Field Isolates}

Sequencing of PCR amplicons produced over 1.5 million raw reads from each sample (Table 3). The read coverage from this isolate was much higher, up to 8000 reads per position, with low reads (34-163 per position) in the GC-rich region between the 4 and $6 \mathrm{~kb}$ genome positions (Figure 4). Similarly, low reads were observed in the leader and trailer regions, as low as 189 and 13 per position, respectively. In the region where a missing region was constructed using the consensus for the Momba sequence, the average read coverage was 84.4 .

Table 3. Results from full-genome sequencing of PPRV field isolates from goats in Ngorongoro and Momba districts of the northern and southern highland of Tanzania, using Oxford Nanopore MinION sequencer.

\begin{tabular}{ccccccccc}
\hline Sample & Raw Reads & Total bp & $\begin{array}{c}\text { N50 Length } \\
\mathbf{( b p )}\end{array}$ & $\begin{array}{c}\text { Reads } \\
\text { Mapped to } \\
\text { PPRV }\end{array}$ & $\begin{array}{c}\text { Average } \\
\text { Coverage } \\
\text { Reads }\end{array}$ & $\begin{array}{c}\text { Genome } \\
\text { Coverage } \\
\mathbf{> 5 0} \times \mathbf{( \% )}\end{array}$ & $\begin{array}{c}\text { Genome } \\
\text { Coverage } \mathbf{2 5} \times \\
\text { (\%) Source }\end{array}$ & $\begin{array}{c}\text { PPRV } \\
\text { Lineage }\end{array}$ \\
\hline Ngorongoro & $1,881,426$ & $2,203,973,564$ & 793 & $1,784,633$ & 4575 & 99.2 & 99.8 & III \\
\hline Momba & $1,712,393$ & $1,605,543,198$ & 816 & $1,688,419$ & 3906 & 98.7 & 99.5 & III \\
\hline
\end{tabular}

\subsection{Annotation of Peste des Petits Ruminants Virus Isolate}

The nanopore sequencing of PPRV field isolates generated full-length genomes with 15,948 nucleotides. The graphical view of the PPRV open-reading frames (ORFs) in comparison with the reference sequence showed that the PPRV genomes encoded six structural proteins with transcription units for the N, P, M, F, H and L proteins, and two non-structural proteins $\mathrm{C}$ and $\mathrm{V}$ transcribed from the $P$ gene, using the genome annotation transfer utility (Figure 5). The Tanzania/Ngorongoro/2016 PPRV isolate showed the highest protein identity with lineage III isolate, KN/2011(KM463083.1), N (99\%), P (99.8\%), V (99.33\%), C (100\%) M (100\%), F (98\%), H (100\%) and L (99.7\%). Equally, high protein identity was observed with the Tanzania/Momba/2018 PPRV isolate, N (99.6\%), P (98.4\%), V (95.97\%), C (97.7\%) M (100\%), F (99.5\%), H (99.3\%) and L (99.4\%). Moreover, the PPRV isolates, Tanzania/2016 and 2018, contained 1080 nucleotides of untranslated region (UTR) at the genome position between nucleotides 4446 and 5526, with 66.9 and $69.4 \%$ GC contents, respectively, between the $\mathrm{M}$ and $\mathrm{F}$ open-reading frames. 


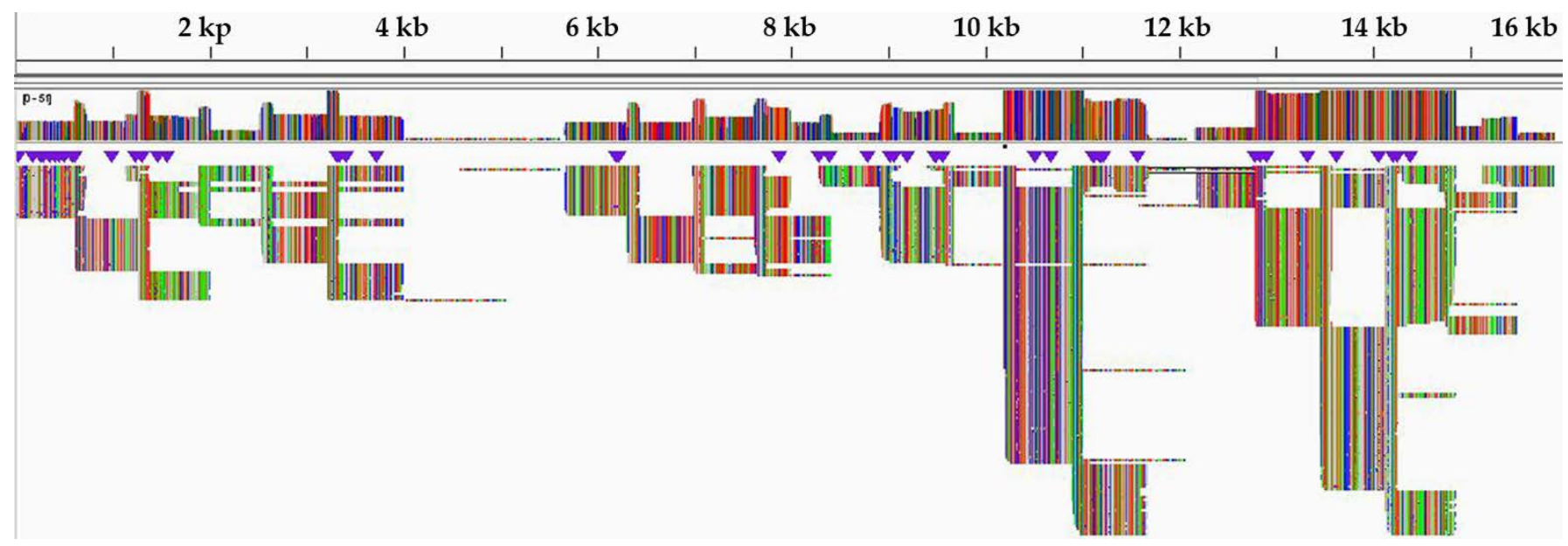

Figure 4. Integrative genomic viewer (IGV) of peste des petits ruminants virus (PPRV) sequence reads against reference genome (KM463083).

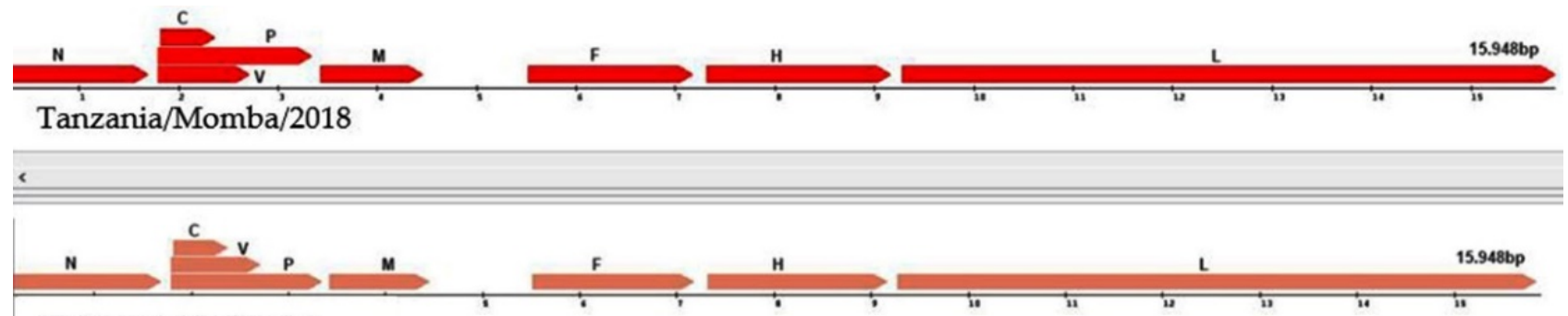

Refseq (NC_006383)

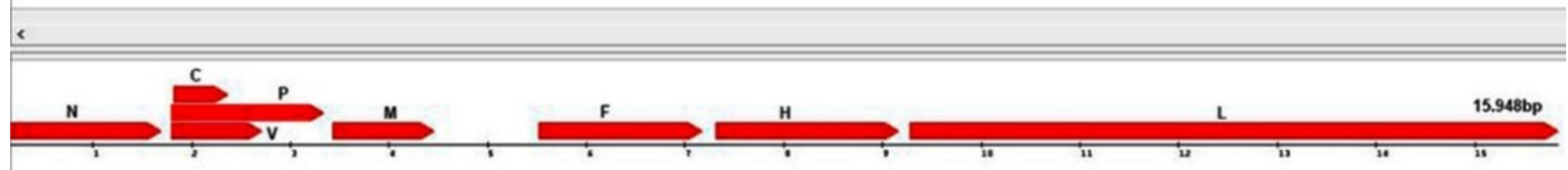

Tanzania/Ngorongoro/2016

Figure 5. Graphical view of peste des petits ruminants virus (PPRV) open-reading frames (ORFs) in comparison with reference sequence (NC_006383), using genome annotation transfer utility.

\subsection{Phylogenetic Analysis of Peste des Petits Ruminants Virus}

Two complete genome sequences obtained from this study were submitted to GenBank and assigned accession numbers MW960272 and MZ322753. Another 19 full genomes representing all the four lineages were retrieved from GenBank for further analysis, making it a total of 21 sequences. The sequences showed good conformity with the PPRV complete genome sequences available on GenBank (Table 4). A phylogenetic analysis of the sequences showed that the PPRV sequences obtained from Loliondo in Ngorongoro and Chilulumo in Momba districts clustered into lineage III of PPRV (Figure 6). The comparison of their full genomes with those of other PPRV strains revealed the highest nucleotide identity (96.19 to 99.24\%) with the PPRV isolate KN5/2011 (KM463083.1) from Kenya; B3 isolate from Burundi (MK686066.1) and Ugandan isolate (KJ867543.1).

\subsection{Temporal-Spatial Spread of Peste des Petits Ruminants Virus}

A Bayesian time-scaled MCC tree using complete PPRV genomes was constructed $(n=40)$, alongside Tanzania/Momba/2018 and Tanzania/Ngorongoro/2016 (Figure 7). In estimation of the route of entry of lineage PPRV III into East Africa, we visualized the summarized results of the Bayesian phylogeographic analysis of the complete genome (Figure 8). Analysis of the posterior probabilities suggests a strong historical and geo- 
graphic connection between the Tanzanian isolates and PPR viruses isolated in East Africa (Figure 9). These analyses show a very strong likelihood $>72 \%$ that the lineage III viruses currently circulating in East Africa are closely related to and, in the absence of further material, likely originated from the Ethiopia 1994 outbreaks (Figure 7).

Table 4. Publicly available complete genome sequences of peste des petits ruminants virus strains from East Africa and selected strains from other parts of Africa and Asia used for comparative genomic analysis in this study.

\begin{tabular}{|c|c|c|c|c|c|c|c|c|}
\hline Isolate Name & GenBank & $\begin{array}{c}\text { Country of } \\
\text { Origin }\end{array}$ & $\begin{array}{c}\text { Year of } \\
\text { Collection }\end{array}$ & Lineage & $\begin{array}{c}\text { Percentage Nucleotide } \\
\text { Identity with } \\
\text { Tanzania /2016 PPRV } \\
\text { Isolate }\end{array}$ & $\begin{array}{l}\text { Percentage Nucleotide } \\
\text { Identity with } \\
\text { Tanzania/ 2018 PPRV } \\
\text { Isolate }\end{array}$ & $\begin{array}{c}\text { Host } \\
\text { Species }\end{array}$ & Reference \\
\hline Tanzania/2016 & MW960272 & Tanzania & 2016 & III & 100.00 & 97.39 & goat & This study \\
\hline Tanzania/2018 & MZ322753 & Tanzania & 2018 & III & 97.39 & 100.00 & goat & This study \\
\hline KN5/2011 & KM463083.1 & Kenya & 2011 & III & 99.24 & 97.92 & goat & {$[60]$} \\
\hline B3 & MK686066.1 & Burundi & 2017 & III & 98.44 & 97.22 & goat & [61] \\
\hline Uganda 2012 & KJ867543.1 & Uganda & 2012 & III & 97.38 & 96.19 & goat & [62] \\
\hline Ethiopia 1994 & KJ867540.1 & Ethiopia & 1994 & III & 95.55 & 95.57 & goat & [62] \\
\hline UAE 1986 & KJ867545.1 & $\begin{array}{l}\text { United Arab } \\
\text { Emirates }\end{array}$ & 1986 & III & 94.49 & 94.57 & $\begin{array}{l}\text { Dorcas } \\
\text { gazelle }\end{array}$ & {$[62]$} \\
\hline Oman 1983 & KJ867544.1 & Oman & 1983 & III & 94.47 & 94.56 & goat & [62] \\
\hline Nigeria/75/1 & HQ197753.1 & Nigeria & 1976 & II & 88.58 & 88.73 & goat & [63] \\
\hline Benin/B1/1969 & KR781450.1 & Benin & 1969 & II & 88.85 & 89.00 & goat & {$[64]$} \\
\hline $\mathrm{Ng} 76 / 1$ & EU267274.1 & Nigeria & 1976 & II & 88.50 & 88.66 & goat & [65] \\
\hline Ghana/2010 & KJ466104.1 & Ghana & 2010 & II & 87.69 & 87.81 & sheep & [66] \\
\hline Benin/10/2011 & KR781449.1 & Benin & 2011 & II & 87.59 & 87.72 & sheep & [64] \\
\hline ICV89 & EU267273.1 & Cote d'Ivoire & 1989 & I & 87.92 & 88.02 & goat & [65] \\
\hline Ethiopia 2010 & KJ867541.1 & Ethiopia & 2010 & IV & 87.20 & 87.35 & goat & [67] \\
\hline Georgia/2016 & MF737202.1 & Georgia & 2016 & IV & 86.94 & 87.04 & sheep & [68] \\
\hline Morocco 2008 & KC594074.1 & Morocco & 2008 & IV & 87.35 & 87.44 & goat & [28] \\
\hline Turkey/2018 & MN657232.1 & Turkey & 2018 & IV & 86.85 & 87.01 & sheep & [69] \\
\hline Mongolia/2016 & KY888168.1 & Mongolia & 2016 & IV & 86.86 & 86.88 & sheep & {$[70]$} \\
\hline China/33/2007 & KX421388.1 & China & 2007 & IV & 87.30 & 87.36 & goat & [71] \\
\hline China/Tibet/07 & FJ905304.1 & China & 2007 & IV & 87.28 & 87.34 & goat & [72] \\
\hline
\end{tabular}
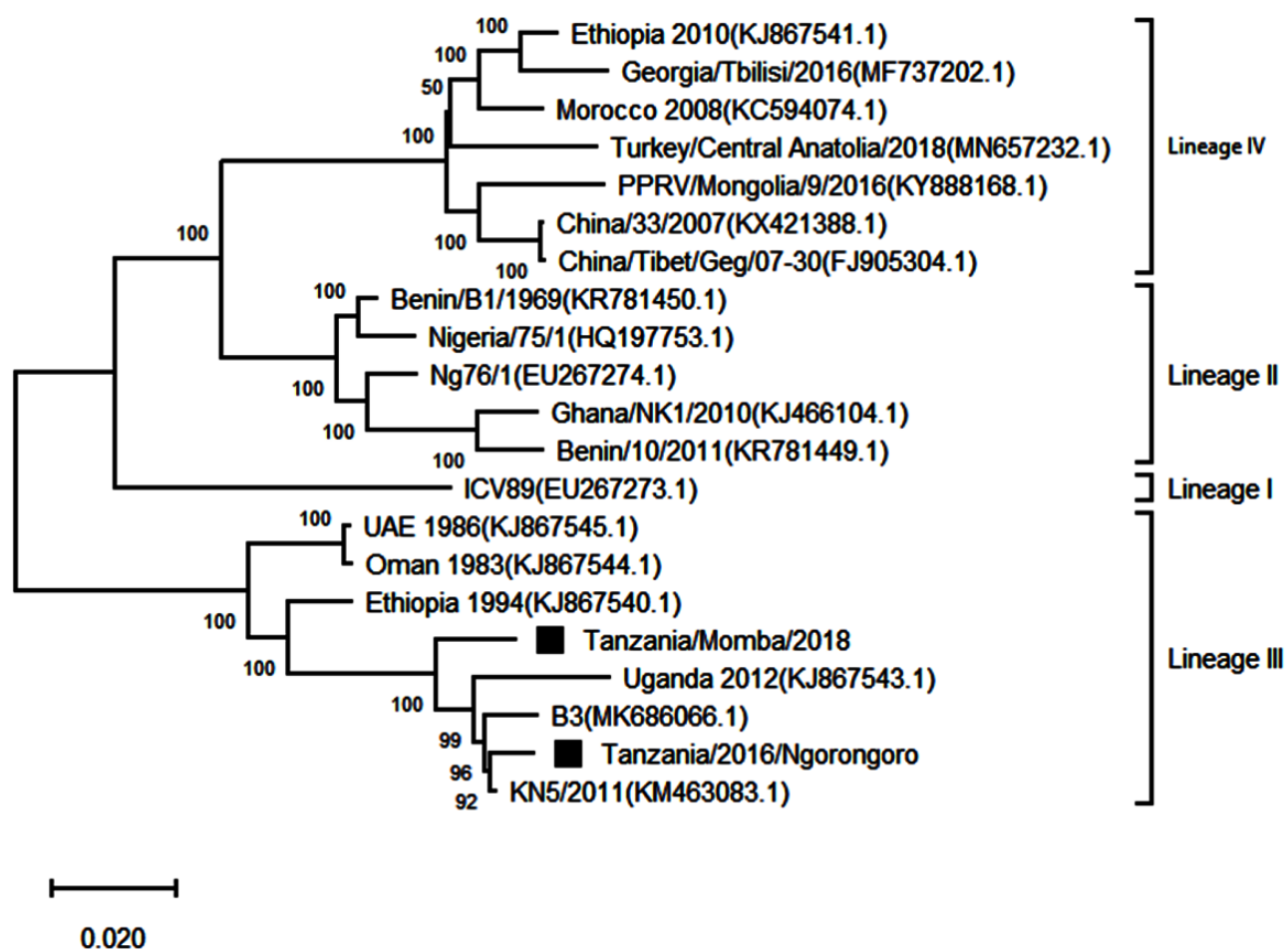

Figure 6. Maximum likelihood phylogenetic tree obtained after multiple sequence alignment of complete genomes of peste des petits ruminants virus strains from East Africa and selected strains from other parts of Africa and Asia. The viruses described in this study are indicated by black squares and the scale bar indicates nucleotide substitution per site, while the node values show percentage of bootstrap support. The analysis involved 21 nucleotide sequences with 15,962 positions in the final dataset. 


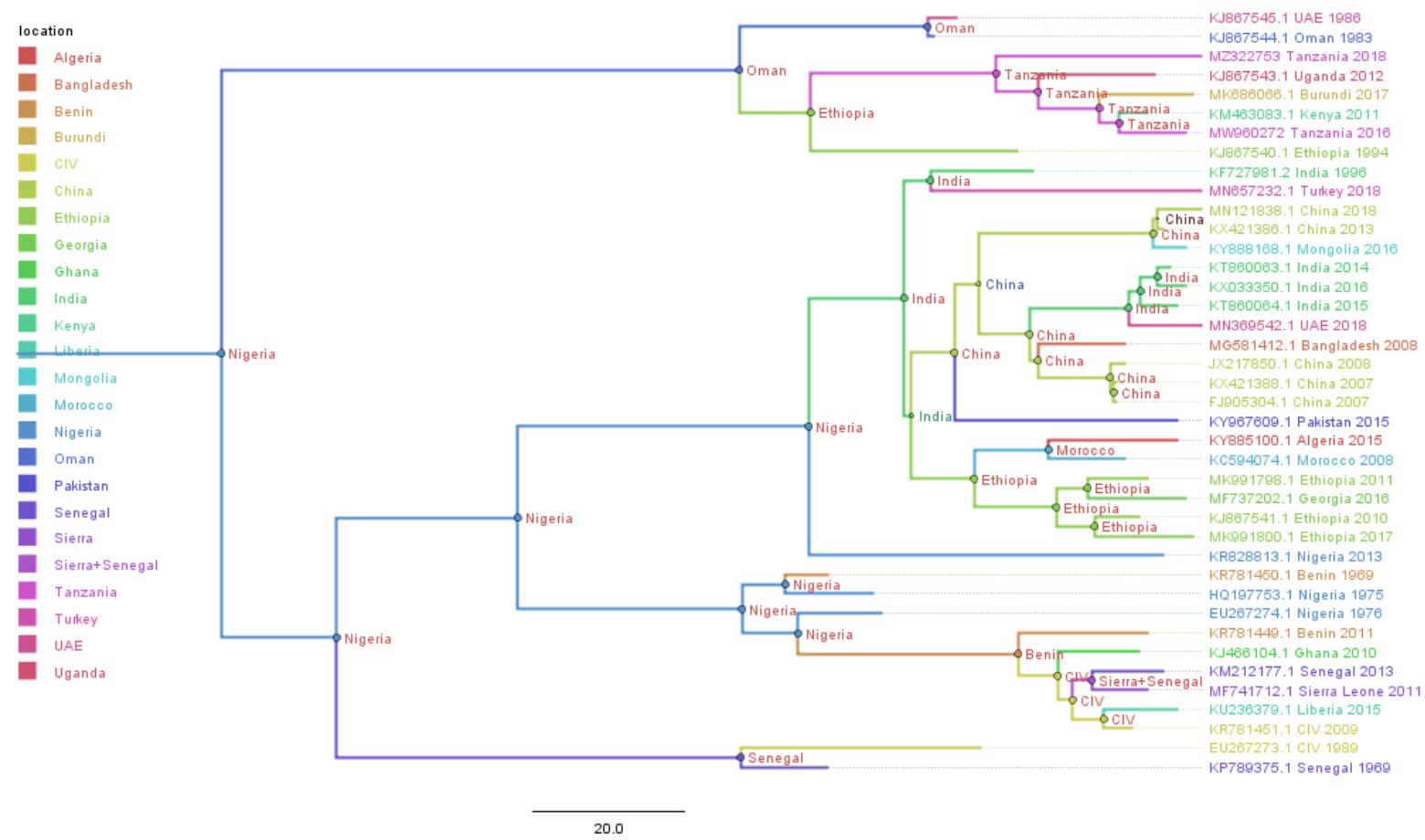

Figure 7. Maximum clade credibility (MCC) trees constructed for the phylogeographical reconstruction of peste des petits ruminants virus PPRV using complete genomes. Posterior probability values are indicated by the size of the node and posterior probability distribution, indicated as a location at the side of each node. Branches are coloured according to the most likely location at the preceding node in the tree. The year of the samples for which PPR viruses were sequenced and GenBank accession numbers are given against each sequence. A phylogeographic method estimated the probability of the root location of an ancestral PPRV and individual lineages as being Nigeria for PPRV, as previously reported by Muniraju et al., 2014

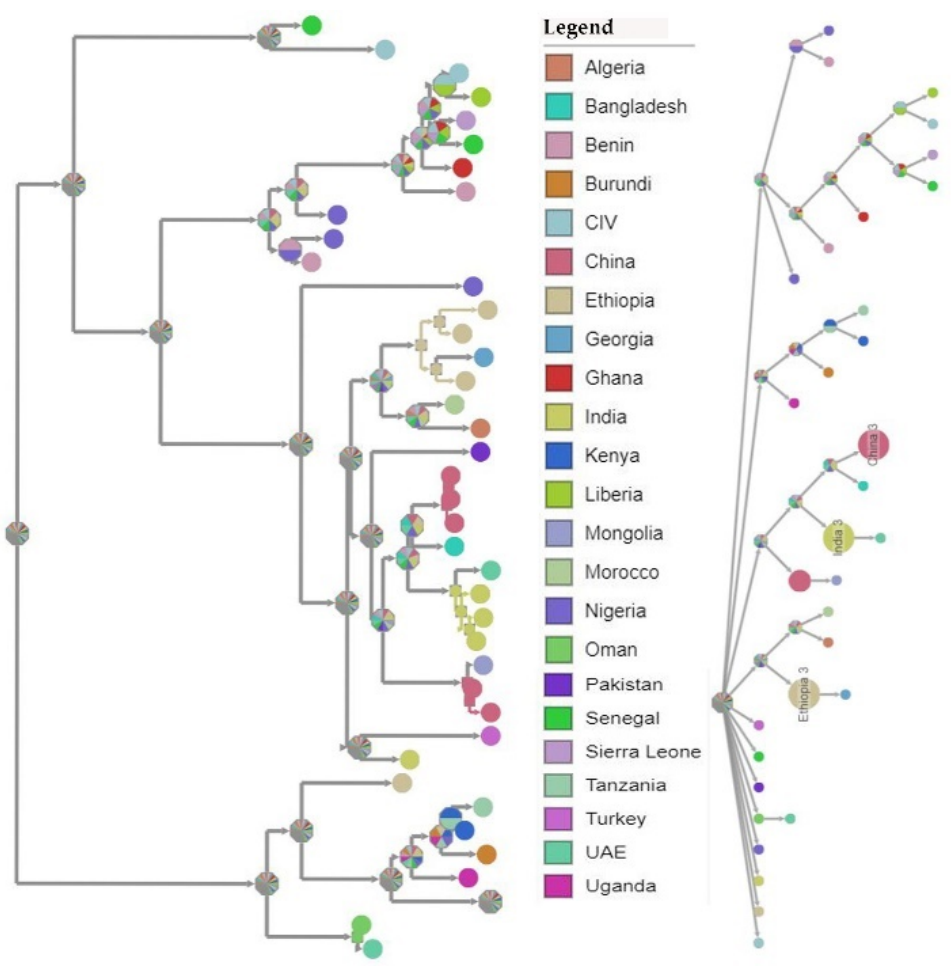

Figure 8. Ancestral rooted phylogenetic map of the selected complete genomes of peste des petits ruminants (PPR) viruses with annotated tips, using maximum likelihood (https:/ / pastml.pasteur.fr/, accessed on 3 May 2021). 


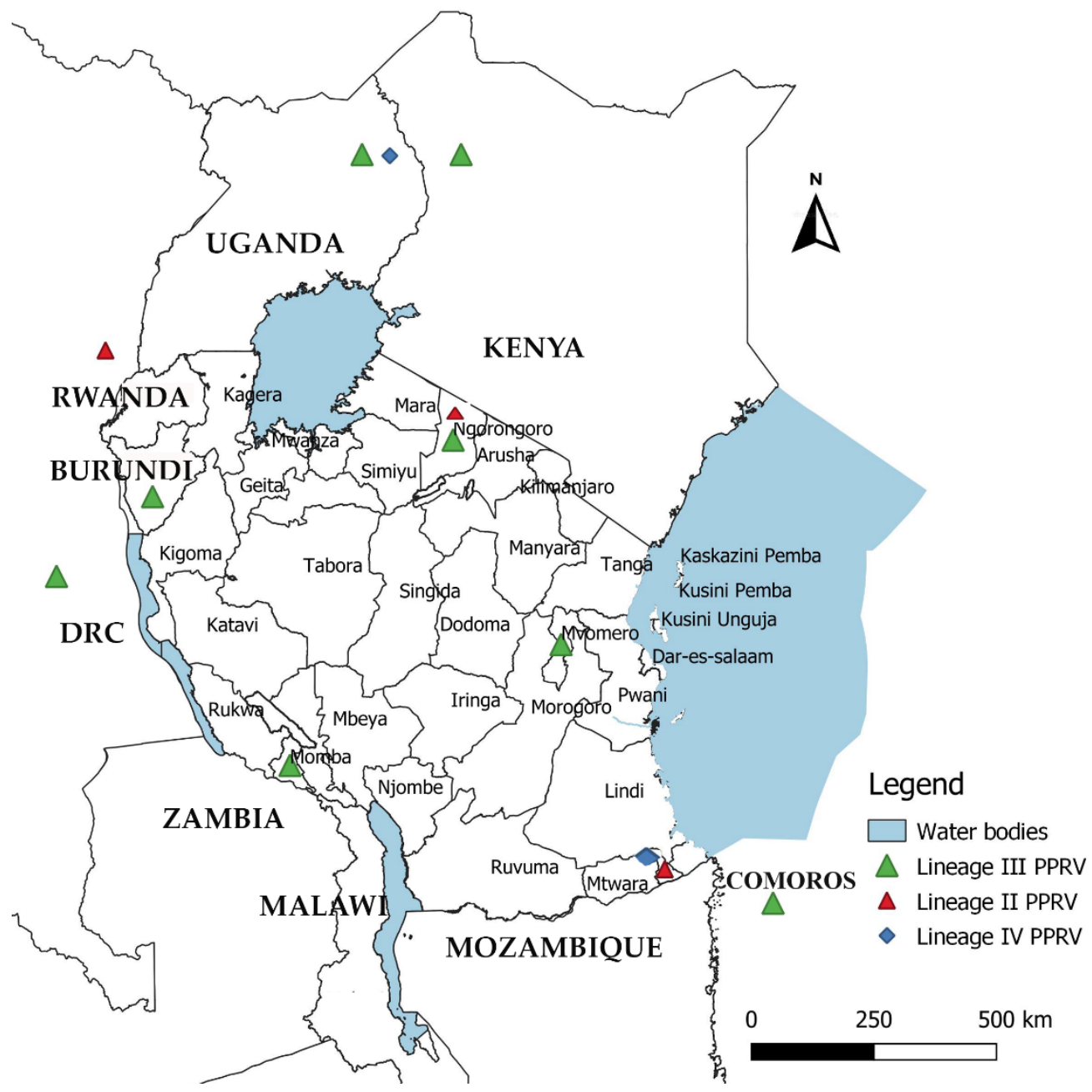

Figure 9. Distribution and molecular characterization of peste des petits ruminants virus in Tanzania and neighbouring countries (Kenya, Uganda, DR Congo, Burundi and Comoros). The colour of triangles and diamonds indicate the viral lineages reported in these countries: lineage III, light green; lineage II, red; and lineage IV, blue. This map was created using QGIS software version 3.16.8 downloaded from https:/ / qgis.org/en/ site/, accessed on 12 June 2021.

\section{Discussion}

Peste des petits ruminants is an economically important transboundary animal disease of sheep and goats, which is targeted for global control and eradication, as a joint initiative of the Food and Agriculture Organisation of the United Nations (FAO) and World Organisation for Animal Health (OIE). Molecular epidemiological surveillance using in-depth genomic data has the potential to clarify the roles of a wide host range in PPRV circulation, direction of transmission at domestic-wildlife interfaces and how viral evolution may alter host range and virulence [73]. However, in many developing countries, access to the required sequencing technology is limited, compounded by the difficulty in transporting wildlife clinical samples across international borders due to the Convention on International Trade in Endangered Species of Wild Fauna and Flora, and Nagoya Protocol regulations [3]. The Oxford nanopore sequencing devices are portable, cheap, require minimal supporting laboratory infrastructure or technical expertise for sample preparation and can be used to perform rapid sequencing analysis with flexible scalability. Thus, the present study was carried out to generate complete genomes of PPRV field isolates using the Oxford nanopore MinION sequencer. With nanopore sequencing, two complete genomes of PPRV were generated within four hours. The resulting sequences had the same length as all of the other PPRV genomes sequenced to date and were in agreement with the "rule of six" for 
paramyxoviruses $[19,20]$. The organization of the genome was the same as those described previously, with transcription units for the $\mathrm{N}, \mathrm{P}(\mathrm{C} / \mathrm{V}), \mathrm{M}, \mathrm{F}, \mathrm{H}$ and $\mathrm{L}$ proteins [9]. The complete genomes generated with this technology comply with molecular epidemiology sequencing standards, as being "Coding complete", which means $90-99 \%$ of the genome is sequenced with no gaps, and that all ORFs are generated (Figure 5).

Following the use of the nanopore sequencing protocol, drop out of amplicons 7, 8 and 9 were observed in the GC-rich region, resulting in no PCR amplicons using this protocol [17]. This bottleneck was resolved by redesigning three pairs of long-read primers for regions 7, 8 and 9, which facilitated the generation of PCR amplicons in this problematic region (Figure 3). The GC-rich region is not conserved between PPRV isolates and poses difficulty for both PCR nucleotide amplification and primer design [74]. Equally, studies have shown that this region has led to the absence of or low nucleotide sequence coverage in the PPRV genome [66]. Next-generation sequencing technologies, such as Illumina and nanopore MinION, generate data of sufficient depth to characterize PPRV strains, but in most cases with no or very low sequence coverage at the GC-rich junction (between nucleotides 4444 and 5526 within the genome) and $3^{\prime}$ and $5^{\prime}$ genome extremities [17]. The missing short sequences are usually amplified using a new set of primers. The genome extremities are also amplified using rapid amplification of cDNA ends by polymerase chain reaction (RACE PCR) [74]. The amplified fragments are later confirmed by Sanger dideoxynucleotide cycle sequencing [69]. Similarly, a systematic drop out of problematic amplicons 18 and 76 was noticed during sequencing of SARS-CoV-2, which has led to the modification of the ARTIC nanopore sequencing protocol [75]. Within this study, the coverage depth was very uneven across the genome (Figure 4). Thus, the accumulation of genetic diversity in PPRV over time may necessitate further changes in the nanopore sequencing protocol. A larger field study is needed to allow the collection of sufficient data to assess the robustness of the protocol.

The sequence coverage was much higher, up to 8000 reads per position (Figure 4). The majority of the reads mapped against the reference genome with an average of $96.73 \%$ (Table 3). This indicated high-quality viral RNA, with no degradation of the viral RNA genomes in selected PPR-positive samples. However, very low reads were observed in the GC-rich region at the genome position between 4 and $6 \mathrm{~kb}$ (Figure 4). The GC-rich region was approximately 1080 nucleotides long, with an average of $68.15 \%$ GC content residing between the M and F genes of PPRV. Equally, previous studies have described that the M and $\mathrm{F}$ untranslated intergenic region is the longest intergenic region in the PPRV genome and is very rich in GC content (66-72\%) [9]. Owing to secondary and hairpin structures in the GC-rich region, this region is an extremely difficult PCR target for both primer design and nucleotide amplification [76]. The development of overlapping long-read primers targeting this region was critically important to generate nucleotide sequences covering this region (Figure 4). Similarly, previous studies have confirmed that the GC-rich and genome extremities were regions with the lowest or absent sequence coverage in all four known PPRV lineages [17].

Genomic comparison of Tanzanian field isolates, together with other available complete genomes of PPRV available on GenBank, showed a high level of sequence conformity, and Tanzanian isolates clustered together with other isolates of lineage III PPRV (Figure 6). Phylogenetic analysis revealed a high nucleotide identity (96.19-99.24\%) with lineage III PPR viruses currently circulating in East Africa, indicating a common origin. The $\mathrm{M}$ and $\mathrm{H}$ sequences were the most conserved of the genes with lineage III PPR viruses in East Africa (Table 4). Equally, previous studies showed that between isolates, the PPRV genome is relatively conserved, with a maximum divergence of $12 \%$ at the nucleotide level and $7 \%$ at the amino acid sequence levels [59]. Further analysis of posterior probabilities suggests a strong historical and geographic connection between the Tanzanian field isolates and PPR viruses isolated in East Africa (Figure 7). These analyses show a very strong likelihood $>72 \%$ that the lineage III viruses currently circulating in East Africa spread from Ethiopia as the most likely origin, although genomic surveillance for PPRV is poor and 
a lack of full-genome sequencing from other regions likely biases this result (Figure 8). A phylogeographic method estimated the probability of the root location of an ancestral PPRV and individual lineages as being Nigeria for PPRV, as previously reported [59]. The phylogeographic reconstruction with spatial and temporal information of PPRV isolates has enabled an understanding of the historic emergence and dispersal patterns involved in PPRV evolution $[29,59]$. As the available number of complete genome sequences is very small in East Africa, to explore the relationship between African virus isolates, further sequences and phylogeographic analyses are needed. As with many other areas, partial sequences are most commonly available but do not enable a thorough analysis of PPRV genetics (Table 1). Certainly, the paucity of full genome data significantly limits the opportunity to evaluate genetic changes outside of the target sequences. Certainly, a more thorough genetic analysis is critical in the study of PPRV pathogenesis and viral evolution studies, alongside the development of novel diagnostics and therapeutic tools for PPR control and eradication (10).

Peste des petits ruminants may have passed unrecognized for several years in some areas of Tanzania, because it is often confused with other diseases that cause respiratory problems and mortality in small ruminant populations [28,29]. A retrospective study that was conducted on archived samples collected from Ngorongoro district between 1998 and 2004 demonstrated anti-PPRV-specific antibodies in samples collected in 2004, indicating that PPR was likely present in Tanzania before it was officially confirmed following diagnostic evaluation in 2008 [35]. The presence of small ruminant diseases that can be considered in differential diagnosis, including bluetongue, contagious caprine pleuropneumonia, Orf disease, capripox and foot and mouth disease, often overlap in syndromic evaluation, leaving laboratory diagnosis as the only mechanism to diagnose PPR $[28,30,31]$. In addition, secondary infection caused by Pasteurella multocida and Mannheimia haemolytica can also complicate syndromic diagnosis [32]. Molecular confirmation of the occurrence of PPR in PPR-free zones and endemic settings is critically important for the accurate diagnosis and confirmation of outbreaks [33].

To enable the successful eradication of PPR, rapid diagnosis remains a cornerstone for the implementation of control measures, including vaccination, quarantine and possible stamping out [36,77]. The wide host susceptibility of species to PPR presents logistic challenges around sampling, diagnosis and diagnostic protocols need to be adequately validated for atypical species affected, and the type of sample being collected [78-80]. The application of Oxford nanopore MinION sequencing technology demonstrated it to be an effective and rapid option for the molecular sequencing of PPRV. Importantly, the sequencing protocol described has been developed and implemented for the sequencing of PPRV in the Molecular Virology Laboratory at Sokoine University of Agriculture in Tanzania as part of this study. This enhanced capability in an endemic setting has demonstrated that Oxford nanopore MinION sequencing is a viable option for minimally equipped diagnostic facilities in low-income and resource-constrained countries. Going forward, the Oxford nanopore MinION sequencer is likely to be an important tool in providing rapid and in-depth genomic information of circulating PPRV strains during the eradication programme. Critically, it will play a significant role in defining PPR outbreaks by enabling the detection of cryptic foci, as well as demonstrating virus circulation in areas where inadequate vaccine deployment may have occurred.

\section{Conclusions}

Two complete genomes of lineage III PPRV from Tanzania field isolates were generated for the first-time using Oxford nanopore MinION, in our Molecular Virology Laboratory at the Sokoine University of Agriculture in Tanzania. The development of this protocol in a resource-limited setting has demonstrated its utility for PPRV and other viral pathogens where full-genome sequence data acquisition is beneficial. Phylogenetic analysis of the complete genomes revealed a high nucleotide identity with lineage III PPR viruses currently circulating in neighbouring countries (Kenya, Burundi and Uganda), indicating a common 
origin. There is a very strong likelihood, $>72 \%$, that the lineage III viruses currently circulating in East Africa spread from the Ethiopia 1994 outbreak as the most likely origin. However, the coverage depth was uneven across the genome, with amplicon dropout at the GC-rich region and genome termini. A larger field study is required to enable the collection of sufficient data to assess the robustness of the nanopore sequencing technology and to validate the protocol.

Author Contributions: Conceptualization, E.K. and G.M.; methodology, E.K., G.M., M.R.M., M.M., S.M., F.N., R.K. and S.P.; software, E.K., M.M. and S.P.; validation, R.K., S.P., G.M., S.O. and S.M.; formal analysis, E.K., C.T. and G.M.; investigation, E.K., T.K. and M.R.M.; resources, M.R., S.P., F.N. and G.M.; data curation, E.K., M.M., C.T. and G.M.; writing—original draft preparation, E.K.; writing—review and editing, M.M., T.K., M.R.M., C.T., F.N., S.O., S.M., R.K., S.P., M.R. and G.M.; supervision, G.M., S.M., R.K., S.O. and S.P. All authors have read and agreed to the published version of the manuscript.

Funding: E.K. is the recipient of a scholarship from the Government of the United Republic of Tanzania through the World Bank (WB-ACE II Grant PAD1436, IDA credit 5799-TZ) to the SACIDS Africa Centre of Excellence for Infectious Diseases of Humans and Animals in Eastern and Southern Africa (SACIDS-ACE) at the SACIDS Foundation for One Health of the Sokoine University of Agriculture (SUA), Tanzania. M.M., C.T. and S.P. were funded by The Pirbright Institute through the Biotechnology and Biological Sciences Research Council (BBSRC), grant numbers BB/L013657/1 BB/T004096/1, BBS/E/I/00007038 and BBS/E/I/0000703. S.P. is a Jenner investigator at Oxford University and a visiting professor at the Royal Veterinary College, London University.

Institutional Review Board Statement: Ethical review and approval were waived for this study, due to the fact that we used laboratory achieved PPRV positive samples that were previously screened for PPR from different outbreaks in Tanzania.

Data Availability Statement: The nanopore datasets generated during this research are publicly available at the NCBI GenBank (accession numbers: MW960272 and MZ322753).

Acknowledgments: The authors wish to thank the Government of the United Republic of Tanzania and World Bank for providing a scholarship grant to E.K. We extend our sincere thanks to Charles Kayuki for his guidance during nanopore library preparation and sequencing. We are thankful to Jean Népomuscène Hakizimana, Gaspary Mwanyika and the ASAP team at The Pirbright Institute for their guidance and assistance during nanopore dataset analysis, as well as Anna Rogath, Mhoja Ndalahwa and Sengiyumva Kandusi for their technical assistance in the laboratory. The authors also acknowledge Ashley C Banyard of the Animal and Plant Health Agency for English editing.

Conflicts of Interest: The authors declare no conflict of interest.

\section{References}

1. Njeumi, F.; Bailey, D.; Soula, J.J; Diop, B.; Tekola, B.G. Eradicating the Scourge of Peste Des Petits Ruminants from the World. Viruses 2020, 12, 313. [CrossRef]

2. Libeau, G.; Diallo, A.; Parida, S. Evolutionary Genetics Underlying the Spread of Peste Des Petits Ruminants Virus. Anim. Front. 2014, 4, 14-20. [CrossRef]

3. Fine, A.E.; Pruvot, M.; Benfield, C.T.O.; Caron, A.; Cattoli, G.; Chardonnet, P.; Dioli, M.; Dulu, T.; Gilbert, M.; Kock, R.; et al. Eradication of Peste Des Petits Ruminants Virus and the Wildlife-Livestock Interface. Front. Vet. Sci. 2020, 7, 50. [CrossRef]

4. Jones, B.A.; Rich, K.M.; Mariner, J.C.; Anderson, J.; Jeggo, M.; Thevasagayam, S.; Cai, Y.; Peters, A.R.; Roeder, P. The Economic Impact of Eradicating Peste Des Petits Ruminants: A Benefit-Cost Analysis. PLoS ONE 2016, 11, e0149982. [CrossRef] [PubMed]

5. FAO; OIE. Global Strategy for the Control and Eradication of PPR. In Proceedings of the International Conference for the Control and Eradication of Peste Des Petits Ruminants (PPR), Abidjan, Côte d'Ivoire, 31 March-2 April 2015; ISBN 978-92-9044-989-8.

6. Elsawalhy, A.; Mariner, J.; Chibeu, D.; Wamwayi, H.; Wakhusama, S.; Olaho-Mukani, W.; Toye, P. Pan African Strategy for the Progressive Control of Peste Des Petits Ruminants (Pan African PPR Strategy). Bull. Anim. Health Prod. Afr. 2011. [CrossRef]

7. Mariner, J.C.; Jones, B.A.; Rich, K.M.; Thevasagayam, S.; Anderson, J.; Jeggo, M.; Cai, Y.; Peters, A.R.; Roeder, P.L. The Opportunity To Eradicate Peste Des Petits Ruminants. J. Immunol. 2016, 196, 3499-3506. [CrossRef] [PubMed]

8. Roeder, P.; Mariner, J.; Kock, R. Rinderpest: The Veterinary Perspective on Eradication. Philos. Trans. R. Soc. B Biol. Sci. 2013, 368, 20120139. [CrossRef]

9. Parida, S.; Muniraju, M.; Mahapatra, M.; Muthuchelvan, D.; Buczkowski, H.; Banyard, A.C. Peste Des Petits Ruminants. Vet. Microbiol. 2015. [CrossRef] [PubMed] 
10. Dundon, W.G.; Diallo, A.; Cattoli, G. Peste Des Petits Ruminants in Africa: A Review of Currently Available Molecular Epidemiological Data, 2020. Arch. Virol. 2020, 162, 2147-2163. [CrossRef]

11. Bataille, A.; Kwiatek, O.; Belfkhi, S.; Mounier, L.; Parida, S.; Mahapatra, M.; Caron, A.; Chubwa, C.C.; Keyyu, J.; Kock, R.; et al. Optimization and Evaluation of a Non-Invasive Tool for Peste Des Petits Ruminants Surveillance and Control. Sci. Rep. 2019, 9, 1-8. [CrossRef]

12. Quick, J.; Loman, N.J.; Duraffour, S.; Simpson, J.T.; Severi, E.; Cowley, L.; Bore, J.A.; Koundouno, R.; Dudas, G.; Mikhail, A.; et al. Real-Time, Portable Genome Sequencing for Ebola Surveillance. Nature 2016, 530, 228-232. [CrossRef]

13. Wang, M.; Fu, A.; Hu, B.; Tong, Y.; Liu, R.; Liu, Z.; Gu, J.; Xiang, B.; Liu, J.; Jiang, W.; et al. Nanopore Targeted Sequencing for the Accurate and Comprehensive Detection of SARS-CoV-2 and Other Respiratory Viruses. Small 2020, 16, 2002169. [CrossRef]

14. Faria, N.R.; Quick, J.; Claro, I.M.; Thézé, J.; de Jesus, J.G.; Giovanetti, M.; Kraemer, M.U.G.; Hill, S.C.; Black, A.; da Costa, A.C.; et al. Establishment and Cryptic Transmission of Zika Virus in Brazil and the Americas. Nature 2017, 546, 406-410. [CrossRef]

15. Ben Chehida, S.; Filloux, D.; Fernandez, E.; Moubset, O.; Hoareau, M.; Julian, C.; Blondin, L.; Lett, J.-M.; Roumagnac, P.; Lefeuvre, P. Nanopore Sequencing Is a Credible Alternative to Recover Complete Genomes of Geminiviruses. Microorganisms 2021, 9, 903. [CrossRef]

16. Amarasinghe, S.L.; Su, S.; Dong, X.; Zappia, L.; Ritchie, M.E.; Gouil, Q. Opportunities and Challenges in Long-Read Sequencing Data Analysis. Genome Biol. 2020, 21, 30. [CrossRef]

17. Torsson, E.; Kgotlele, T.; Misinzo, G.; Johansson Wensman, J.; Berg, M.; Karlsson Lindsjö, O. Field-Adapted Full Genome Sequencing of Peste-Des-Petits-Ruminants Virus Using Nanopore Sequencing. Front. Vet. Sci. 2020, 7, 858. [CrossRef] [PubMed]

18. Gibbs, E.P.; Taylor, W.P.; Lawman, M.J.; Bryant, J.; Gibbs, D.P.J.; Taylormichael, W.P.; Lawman, J.P.; Bryant, J. Classification of Peste Des Petits Ruminants Virus as the Fourth Member of the Genus Morbillivirus. Intervirology 1979, 11, 268-274. [CrossRef]

19. Bailey, D.; Banyard, A.; Dash, P.; Ozkul, A.; Barrett, T. Full Genome Sequence of Peste Des Petits Ruminants Virus, a Member of the Morbillivirus Genus. Virus Res. 2005, 110, 119-124. [CrossRef] [PubMed]

20. Bao, J.; Wang, Q.; Zhang, Y.; Liu, C.; Li, L.; Wang, Z. Complete Genome Sequence of a Novel Variant Strain of Peste Des Petits Ruminants Virus, China/XJYL/2013. Genome Announc. 2014, 2. [CrossRef] [PubMed]

21. Bailey, D.; Chard, L.S.; Dash, P.; Barrett, T.; Banyard, A.C. Reverse Genetics for Peste-Des-Petits-Ruminants Virus (PPRV): Promoter and Protein Specificities. Virus Res. 2007, 126, 250-255. [CrossRef]

22. Mahapatra, M.; Parida, S.; Egziabher, B.G.; Diallo, A.; Barrett, T. Sequence Analysis of the Phosphoprotein Gene of Peste Des Petits Ruminants (PPR) Virus: Editing of the Gene Transcript. Virus Res. 2003, 96, 85-98. [CrossRef]

23. Balamurugan, V.; Roy, M.; Sowjanyakumari, S.; Abraham, S.; Apsana, R.; Nagalingam, M.; Hemadri, D.; Rahman, H. Development of Recombinant Nucleocapsid Protein Based Indirect ELISA for Serodiagnosis of Peste Des Petits Ruminants in Sheep and Goats. Adv. Anim. Vet. Sci. 2016, 4, 301-310. [CrossRef]

24. Kwiatek, O.; Minet, C.; Grillet, C.; Hurard, C.; Carlsson, E.; Karimov, B.; Albina, E.; Diallo, A.; Libeau, G. Peste Des Petits Ruminants (PPR) Outbreak in Tajikistan. J. Comp. Pathol. 2007, 136, 111-119. [CrossRef]

25. Kwiatek, O.; Ali, Y.H.; Saeed, I.K.; Khalafalla, A.I.; Mohamed, O.I.; Obeida, A.A.; Abdelrahman, M.B.; Osman, H.M.; Taha, K.M.; Abbas, Z.; et al. Asian Lineage of Peste Des Petits Ruminants Virus, Africa. Emerg. Infect. Dis. 2011, 17, 1223-1231. [CrossRef]

26. Couacy-Hymann, E.; Roger, F.; Hurard, C.; Guillou, J.P.; Libeau, G.; Diallo, A. Rapid and Sensitive Detection of Peste Des Petits Ruminants Virus by a Polymerase Chain Reaction Assay. J. Virol. Methods 2002, 100, 17-25. [CrossRef]

27. Forsyth, M.A.; Barrett, T. Evaluation of Polymerase Chain Reaction for the Detection and Characterisation of Rinderpest and Peste Des Petits Ruminants Viruses for Epidemiological Studies. Virus Res. 1995, 39, 151-163. [CrossRef]

28. Muniraju, M.; Harrak, M.E.; Bao, J.; Parthiban, A.B.R.; Banyard, A.C.; Batten, C.; Parida, S. Complete Genome Sequence of a Peste Des Petits Ruminants Virus Recovered from an Alpine Goat during an Outbreak in Morocco in 2008. Genome Announc. 2013, 1 , e00096-13. [CrossRef] [PubMed]

29. Baazizi, R.; Mahapatra, M.; Clarke, B.D.; Ait-Oudhia, K.; Khelef, D.; Parida, S. Peste Des Petits Ruminants (PPR): A Neglected Tropical Disease in Maghreb Region of North Africa and Its Threat to Europe. PLoS ONE 2017, 12, e0175461. [CrossRef] [PubMed]

30. Maganga, G.D.; Verrier, D.; Zerbinati, R.M.; Drosten, C.; Drexler, J.F.; Leroy, E.M. Molecular Typing of PPRV Strains Detected during an Outbreak in Sheep and Goats in South-Eastern Gabon in 2011. Virol. J. 2013, 10, 1. [CrossRef] [PubMed]

31. Kumar, K.S.; Babu, A.; Sundarapandian, G.; Roy, P.; Thangavelu, A.; Kumar, K.S.; Arumugam, R.; Banyard, A.C.; Manohar, B.M.; Parida, S. Molecular Characterisation of Lineage IV Peste Des Petits Ruminants Virus Using Multi Gene Sequence Data. Vet. Microbiol. 2014, 174, 39-49. [CrossRef]

32. Woma, T.Y.; Qasim, A.M.M.; Sabi, A.A.; Abraham, M.N.; Olaiya, O.D.; Bailey, D.; Shamaki, D. Co-Circulation of Peste-Des-PetitsRuminants Virus Asian Lineage IV with Lineage II in Nigeria. Transbound. Emerg. Dis. 2016, 63, 235-242. [CrossRef]

33. Wambura, P. Serological Evidence of the Absence of Peste Des Petits Ruminants in Tanzania. Vet. Rec. 2000, 146, 473-474. [CrossRef]

34. Swai, E.S.; Kapaga, A.; Kivaria, F.; Tinuga, D.; Joshua, G.; Sanka, P. Prevalence and Distribution of Peste Des Petits Ruminants Virus Antibodies in Various Districts of Tanzania. Vet. Res. Commun. 2009, 33, 927-936. [CrossRef]

35. Karimuribo, E.D.; Loomu, P.M.; Mellau, L.S.B.; Swai, E.S. Retrospective Study on Sero-Epidemiology of Peste Des Petits Ruminants before Its Official Confirmation in Northern Tanzania in 2008. Res. Opin. Anim. Vet. Sci. 2010, 1, $184-187$.

36. Kinimi, E.; Odongo, S.; Muyldermans, S.; Kock, R.; Misinzo, G. Paradigm Shift in the Diagnosis of Peste Des Petits Ruminants: Scoping Review. Acta Vet. Scand. 2020, 62, 7. [CrossRef] 
37. Diallo, A.; Barrett, T.; Barbron, M.; Meyer, G.; Lefevre, P.C. Cloning of the Nucleocapsid Protein Gene of Peste-Des-PetitsRuminants Virus: Relationship to Other Morbilliviruses. J. Gen. Virol. 1994, 75, 233-237. [CrossRef]

38. Meyer, G.; Diallo, A. The Nucleotide Sequence of the Fusion Protein Gene of the Peste Des Petits Ruminants Virus: The Long Untranslated Region in the 5'-End of the F-Protein Gene of Morbilliviruses Seems to Be Specific to Each Virus. Virus Res. 1995, 37, 23-35. [CrossRef]

39. Kwiatek, O.; Keita, D.; Gil, P.; Fernández-Pinero, J.; Jimenez Clavero, M.A.; Albina, E.; Libeau, G. Quantitative One-Step Real-Time RT-PCR for the Fast Detection of the Four Genotypes of PPRV. J. Virol. Methods 2010, 165, 168-177. [CrossRef] [PubMed]

40. Kivaria, F.M.; Kwiatek, O.; Kapaga, A.M.; Swai, E.S.; Libeau, G.; Moshy, W.; Mbyuzi, A.O.; Gladson, J. The Incursion, Persistence and Spread of Peste Des Petits Ruminants in Tanzania: Epidemiological Patterns and Predictions. Onderstepoort J. Vet. Res. 2014, 80, 1-10. [CrossRef] [PubMed]

41. Muse, E.A.; Karimuribo, E.D.; Gitao, G.C.; Misinzo, G.; Mellau, L.S.B.; Msoffe, P.L.M.; Swai, E.S.; Albano, M.O. Epidemiological Investigation into the Introduction and Factors for Spread of Peste Des Petits Ruminants, Southern Tanzania. Onderstepoort J. Vet. Res. 2012, 79, 1-6. [CrossRef] [PubMed]

42. Kgotlele, T.; Kasanga, C.J.; Kusiluka, L.J.M.; Misinzo, G. Preliminary Investigation on Presence of Peste Des Petits Ruminants in Dakawa, Mvomero District, Morogoro Region, Tanzania. Onderstepoort J. Vet. Res. 2014, 81, 1-3. [CrossRef]

43. Kgotlele, T.; Macha, E.S.; Kasanga, C.J.; Kusiluka, L.J.M.; Karimuribo, E.D.; Van Doorsselaere, J.; Wensman, J.J.; Munir, M.; Misinzo, G. Partial Genetic Characterization of Peste Des Petits Ruminants Virus from Goats in Northern and Eastern Tanzania. Transbound. Emerg. Dis. 2014, 61, 56-62. [CrossRef]

44. Mahapatra, M.; Sayalel, K.; Muniraju, M.; Eblate, E.; Fyumagwa, R.; Shilinde, L.; Mdaki, M.; Keyyu, J.; Parida, S.; Kock, R. Spillover of Peste Des Petits Ruminants Virus from Domestic to Wild Ruminants in the Serengeti Ecosystem, Tanzania. Emerg. Infect. Dis. 2015, 21, 2230-2234. [CrossRef]

45. Misinzo, G.; Kgotlele, T.; Muse, E.; Doorsselaere, J.; Berg, M.; Munir, M. Peste Des Petits Ruminants Virus Lineage II and IV From Goats in Southern Tanzania During an Outbreak in 2011. Br. J. Virol. 2015, 2, 1-4.

46. Jones, B.A.; Mahapatra, M.; Chubwa, C.; Clarke, B.; Batten, C.; Hicks, H.; Henstock, M.; Keyyu, J.; Kock, R.; Parida, S. Characterisation of Peste Des Petits Ruminants Disease in Pastoralist Flocks in Ngorongoro District of Northern Tanzania and Bluetongue Virus Co-Infection. Viruses 2020, 12, 389. [CrossRef] [PubMed]

47. Kgotlele, T.; Chota, A.; Chubwa, C.C.; Nyasebwa, O.; Lyimo, B.; Torsson, E.; Karimuribo, E.; Kasanga, C.J.; Wensman, J.J.; Misinzo, G.; et al. Detection of Peste Des Petits Ruminants and Concurrent Secondary Diseases in Sheep and Goats in Ngorongoro District, Tanzania. Comp. Clin. Pathol. 2019, 28, 755-759. [CrossRef]

48. Chota, A.; Shirima, G.; Kusiluka, L. Detection of Contagious Caprine Pleuropneumonia and Concurrent Diseases in Outbreaks Presenting with Respiratory Signs in Small Ruminants in Tanzania. Int. J. Trop. Dis. Health 2020. [CrossRef]

49. Afgan, E.; Baker, D.; van den Beek, M.; Blankenberg, D.; Bouvier, D.; Čech, M.; Chilton, J.; Clements, D.; Coraor, N.; Eberhard, C.; et al. The Galaxy Platform for Accessible, Reproducible and Collaborative Biomedical Analyses: 2016 Update. Nucleic Acids Res. 2016, 44, W3-W10. [CrossRef] [PubMed]

50. Wick, R.R.; Judd, L.M.; Gorrie, C.L.; Holt, K.E. Completing Bacterial Genome Assemblies with Multiplex MinION Sequencing. Microb. Genomics 2017, 3. [CrossRef] [PubMed]

51. De Coster, W.; D’Hert, S.; Schultz, D.T.; Cruts, M.; Van Broeckhoven, C. NanoPack: Visualizing and Processing Long-Read Sequencing Data. Bioinformatics 2018, 34, 2666-2669. [CrossRef]

52. Li, H. Minimap2: Pairwise Alignment for Nucleotide Sequences. Bioinformatics 2018, 34, 3094-3100. [CrossRef] [PubMed]

53. Li, H.; Handsaker, B.; Wysoker, A.; Fennell, T.; Ruan, J.; Homer, N.; Marth, G.; Abecasis, G.; Durbin, R. The Sequence Alignment/Map Format and SAMtools. Bioinformatics 2009, 25, 2078-2079. [CrossRef]

54. Koren, S.; Walenz, B.P.; Berlin, K.; Miller, J.R.; Bergman, N.H.; Phillippy, A.M. Canu: Scalable and Accurate Long-Read Assembly via Adaptive k-Mer Weighting and Repeat Separation. Genome Res. 2017, 27, 722-736. [CrossRef]

55. Vaser, R.; Sović, I.; Nagarajan, N.; Šikić, M. Fast and Accurate de Novo Genome Assembly from Long Uncorrected Reads. Genome Res. 2017, 27, 737-746. [CrossRef]

56. Genome Annotation Transfer Utility (GATU): Rapid Annotation of Viral Genomes Using a Closely Related Reference Genome I BMC Genomics I Full Text. Available online: https://bmcgenomics.biomedcentral.com/articles/10.1186/1471-2164-7-150 (accessed on 8 October 2021).

57. Kumar, S.; Stecher, G.; Li, M.; Knyaz, C.; Tamura, K. MEGA X: Molecular Evolutionary Genetics Analysis across Computing Platforms. Mol. Biol. Evol. 2018. [CrossRef]

58. Drummond, A.J.; Suchard, M.A.; Xie, D.; Rambaut, A. Bayesian Phylogenetics with BEAUti and the BEAST 1.7. Mol. Biol. Evol. 2012, 29, 1969-1973. [CrossRef]

59. Muniraju, M.; Munir, M.; Parthiban, A.R.; Banyard, A.C.; Bao, J.; Wang, Z.; Ayebazibwe, C.; Ayelet, G.; El Harrak, M.; Mahapatra, M.; et al. Molecular Evolution of Peste Des Petits Ruminants Virus. Emerg. Infect. Dis. 2014. [CrossRef]

60. Dundon, W.G.; Kihu, S.M.; Settypalli, T.B.K.; Gitao, G.C.; Bebora, L.C.; John, N.M.; Oyugi, J.O.; Silber, R.; Loitsch, A.; Diallo, A. First Complete Genome Sequence of a Lineage III Peste Des Petits Ruminants Virus. Genome Announc. 2014, 2. [CrossRef]

61. Niyokwishimira, A.; de D Baziki, J.; Dundon, W.G.; Nwankpa, N.; Njoroge, C.; Boussini, H.; Wamwayi, H.; Jaw, B.; Cattoli, G.; Nkundwanayo, C.; et al. Detection and Molecular Characterization of Peste Des Petits Ruminants Virus from Outbreaks in Burundi, December 2017-January 2018. Transbound. Emerg. Dis. 2019, 66, 2067-2073. [CrossRef] [PubMed] 
62. Muniraju, M.; Munir, M.; Banyard, A.C.; Ayebazibwe, C.; Wensman, J.; Zohari, S.; Berg, M.; Parthiban, A.B.R.; Mahapatra, M.; Libeau, G.; et al. Complete Genome Sequences of Lineage III Peste Des Petits Ruminants Viruses from the Middle East and East Africa. Genome Announc. 2014. [CrossRef] [PubMed]

63. Hu, Q.; Chen, W.; Huang, K.; Baron, M.D.; Bu, Z. Rescue of Recombinant Peste Des Petits Ruminants Virus: Creation of a GFP-Expressing Virus and Application in Rapid Virus Neutralization Test. Vet. Res. 2012, 43, 1-8. [CrossRef]

64. Adombi, C.M.; Waqas, A.; Dundon, W.G.; Li, S.; Daojin, Y.; Kakpo, L.; Aplogan, G.L.; Diop, M.; Lo, M.M.; Silber, R.; et al. Peste Des Petits Ruminants in Benin: Persistence of a Single Virus Genotype in the Country for Over 42 Years. Transbound. Emerg. Dis. 2017, 64, 1037-1044. [CrossRef]

65. Chard, L.S.; Bailey, D.S.; Dash, P.; Banyard, A.C.; Barrett, T. Full Genome Sequences of Two Virulent Strains of Peste-Des-Petits Ruminants Virus, the Côte d'Ivoire 1989 and Nigeria 1976 Strains. Virus Res. 2008, 136, 192-197. [CrossRef] [PubMed]

66. Dundon, W.G.; Adombi, C.; Waqas, A.; Otsyina, H.R.; Arthur, C.T.; Silber, R.; Loitsch, A.; Diallo, A. Full Genome Sequence of a Peste Des Petits Ruminants Virus (PPRV) from Ghana. Virus Genes 2014, 49, 497-501. [CrossRef] [PubMed]

67. Muniraju, M.; Mahapatra, M.; Ayelet, G.; Babu, A.; Olivier, G.; Munir, M.; Libeau, G.; Batten, C.; Banyard, A.C.; Parida, S. Emergence of Lineage IV Peste Des Petits Ruminants Virus in Ethiopia: Complete Genome Sequence of an Ethiopian Isolate 2010. Transbound. Emerg. Dis. 2016, 63, 435-442. [CrossRef]

68. Rajko-Nenow, P.Z.; Cunliffe, T.G.; Flannery, J.T.; Ropiak, H.M.; Avaliani, L.; Donduashvili, M.; Baron, M.D.; Batten, C.A. Complete Genome Sequence of Peste Des Petits Ruminants Virus from Georgia, 2016. Genome Announc. 2017, 5. [CrossRef] [PubMed]

69. Hacioğlu, S.; King, S.; Çizmeci, Ş.G.; Yeşil, Ö.; Flannery, J.; Baron, M.D.; Batten, C.; Rajko-Nenow, P.Z. Complete Genome Sequence of a Lineage IV Peste Des Petits Ruminants Virus from Turkey, 2018. Microbiol. Resour. Announc. 2020. [CrossRef]

70. Shatar, M.; Khanui, B.; Purevtseren, D.; Khishgee, B.; Loitsch, A.; Unger, H.; Settypalli, T.B.K.; Cattoli, G.; Damdinjav, B.; Dundon, W.G. First Genetic Characterization of Peste Des Petits Ruminants Virus from Mongolia. Arch. Virol. 2017, 162, 3157-3160. [CrossRef] [PubMed]

71. Bao, J.; Wang, Q.; Li, L.; Liu, C.; Zhang, Z.; Li, J.; Wang, S.; Wu, X.; Wang, Z. Evolutionary Dynamics of Recent Peste Des Petits Ruminants Virus Epidemic in China during 2013-2014. Virology 2017, 510, 156-164. [CrossRef]

72. Li, L.; Bao, J.; Wu, X.; Wang, Z.; Wang, J.; Gong, M.; Liu, C.; Li, J. Rapid Detection of Peste Des Petits Ruminants Virus by a Reverse Transcription Loop-Mediated Isothermal Amplification Assay. J. Virol. Methods 2010, 170, 37-41. [CrossRef] [PubMed]

73. Munir, M.; Shabbir, M.Z. A Comparative Phylogenomic Analysis of Peste Des Petits Ruminants Virus Isolated from Wild and Unusual Hosts. Mol. Biol. Rep. 2019, 46, 5587-5593. [CrossRef]

74. Eloiflin, R.J.; Boyer, M.; Kwiatek, O.; Guendouz, S.; Loire, E.; Servan de Almeida, R.; Libeau, G.; Bataille, A. Evolution of Attenuation and Risk of Reversal in Peste Des Petits Ruminants Vaccine Strain Nigeria 75/1. Viruses 2019, 11, 724. [CrossRef] [PubMed]

75. Tyson, J.R.; James, P.; Stoddart, D.; Sparks, N.; Wickenhagen, A.; Hall, G.; Choi, J.H.; Lapointe, H.; Kamelian, K.; Smith, A.D.; et al. Improvements to the ARTIC Multiplex PCR Method for SARS-CoV-2 Genome Sequencing Using Nanopore. bioRxiv 2020 [CrossRef]

76. Mamedov, T.G.; Pienaar, E.; Whitney, S.E.; TerMaat, J.R.; Carvill, G.; Goliath, R.; Subramanian, A.; Viljoen, H.J. A Fundamental Study of the PCR Amplification of GC-Rich DNA Templates. Comput. Biol. Chem. 2008. [CrossRef] [PubMed]

77. Kamel, M.; El-sayed, A. Toward Peste Des Petits Virus ( PPRV ) Eradication: Diagnostic Approaches, Novel Vaccines, and Control Strategies. Virus Res. 2019, 274, 197774. [CrossRef] [PubMed]

78. Benfield, C.T.O.; Hill, S.; Shatar, M.; Shiilegdamba, E.; Damdinjav, B.; Fine, A.; Willett, B.; Kock, R.; Bataille, A. Molecular Epidemiology of Peste Des Petits Ruminants Virus Emergence in Critically Endangered Mongolian Saiga Antelope and Other Wild Ungulates. bioRxiv 2021. [CrossRef]

79. Kinimi, E.; Muyldermans, S.; Vincke, C.; Odongo, S.; Kock, R.; Parida, S.; Mahapatra, M.; Misinzo, G. Development of Nanobodies Targeting Peste Des Petits Ruminants Virus: The Prospect in Disease Diagnosis and Therapy. Animals 2021, 11, 2206. [CrossRef] [PubMed]

80. Jones, B.A.; Mahapatra, M.; Mdetele, D.; Keyyu, J.; Gakuya, F.; Eblate, E.; Lekolool, I.; Limo, C.; Ndiwa, J.N.; Hongo, P.; et al. Peste Des Petits Ruminants Virus Infection at the Wildlife-Livestock Interface in the Greater Serengeti Ecosystem, 2015-2019. Viruses 2021, 13, 838. [CrossRef] 